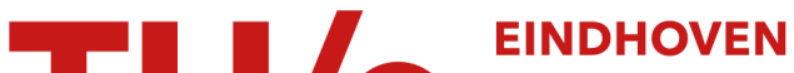 UNIVERSITY OF TECHNOLOGY
}

\section{The conductance of suspensions with conducting particles}

Citation for published version (APA):

Sonneveld, P. J., Visscher, W., Panneflek, F., Barendrecht, E., \& Michels, M. A. J. (1992). The conductance of suspensions with conducting particles. Journal of Applied Electrochemistry, 22(10), 935-949.

https://doi.org/10.1007/BF01024142

DOI:

10.1007/BF01024142

Document status and date:

Published: 01/01/1992

\section{Document Version:}

Publisher's PDF, also known as Version of Record (includes final page, issue and volume numbers)

\section{Please check the document version of this publication:}

- A submitted manuscript is the version of the article upon submission and before peer-review. There can be important differences between the submitted version and the official published version of record. People interested in the research are advised to contact the author for the final version of the publication, or visit the $\mathrm{DOI}$ to the publisher's website.

- The final author version and the galley proof are versions of the publication after peer review.

- The final published version features the final layout of the paper including the volume, issue and page numbers.

Link to publication

\section{General rights}

Copyright and moral rights for the publications made accessible in the public portal are retained by the authors and/or other copyright owners and it is a condition of accessing publications that users recognise and abide by the legal requirements associated with these rights.

- Users may download and print one copy of any publication from the public portal for the purpose of private study or research.

- You may not further distribute the material or use it for any profit-making activity or commercial gain

- You may freely distribute the URL identifying the publication in the public portal.

If the publication is distributed under the terms of Article $25 f a$ of the Dutch Copyright Act, indicated by the "Taverne" license above, please follow below link for the End User Agreement:

www.tue.nl/taverne

Take down policy

If you believe that this document breaches copyright please contact us at:

openaccess@tue.nl

providing details and we will investigate your claim. 


\title{
The conductance of suspensions with conducting particles
}

\author{
P. J. SONNEVELD*, W. VISSCHER*, F. PANNEFLEK* , E. BARENDRECHT*, \\ M. A. J. MICHELS ${ }^{\ddagger \S}$ \\ Laboratory of Inorganic Chemistry and Catalysis* and Department of Theoretical Physics $\$$, \\ Eindhoven University of Technology, P.O. Box 513, 5600 MB Eindhoven, The Netherlands
}

Received 5 March 1991; revised 27 March 1991

The conductance of conductive ceramics, graphite and metal suspensions in aqueous $\mathrm{KOH}$ solutions was measured with the impedance technique using a four-electrode cell. The measurements were carried out for volume fractions up to high viscosities with particles of different sizes. A wide frequency range was used to investigate also the effect of particle-surface polarisation on the conductance. The results have been analysed in terms of the asymmetric and symmetric theories of Bruggeman and the GEM theory for a wide volume-fraction range of suspended particles. Depending on the suspended material, particle size and electrolyte properties, the suspensions reveal flocculation or chain formation. In case of chain formation, sometimes a decrease of the polarisation resistivity is found due to shortcircuiting by direct particle-particle contact. The conductivities of the particles phase, calculated from measured values, are orders lower than predicted from conductivity data of the pure materials. This is attributed to the occurrence of a constriction resistance and film resistance between the particles in the case of flocculation or chain formation as well as to poor wetting of the particles.

\section{Introduction}

Two-phase media-like suspensions can be characterized by macroscopic properties such as an effective conductivity. A comprehensive review on this subject has been given by Landauer [1]. Starting from Maxwell's relation for the conductivity [1-4], Bruggeman developed an asymmetric theory [1, 3-6] for the conductivity of a suspension. This theory is applicable for a larger range of volume fractions of particles than Maxwell's theory, but appears to be valid only for a wide distribution of particle sizes. Meredith and Tobias [6] have developed a model, also based on Maxwell's equation, for particles with a narrow size distribution. The occurrence of chain formation or other direct contacts between the particles leads to a percolation threshold, which can be defined with Bruggeman's symmetric or effective-medium theory $[1,4,7]$. The more recent General Effective-Medium or GEM theory, introduced by McLachlan [8-10], incorporates both Bruggeman theories and gives a good agreement with most of the experimental results.

Suspensions with nonconducting particles $[3,11,12]$ show a conductivity behaviour that can be explained with the equation of Maxwell and the asymmetric theory of Bruggeman; Fricke [12] has also taken into account the shape of the particles. Conductivities of ion-conducting emulsions were measured by Meredith and Tobias [4, 6], Pearce [13], Bhattacharya et al. [15], Lagourette [16] (who also determined the frequency dependency), Fang et al. [17] (who found a very good affirmation of Bruggeman's symmetric theory), and Turner [18]. In this last investigation a simple theory was developed based on the calculation of the distances between ion-conducting spheres; it agrees well with the experimental results for high volume fractions.

Suspensions with conducting metallic particles in electrolytes, such as in fluidized-bed systems were investigated with d.c. by LeGoff et al. [19], Hiddleston et al. [20] and Kreysa [21]. Conductivities measured with a.c. can give information about the particlesurface polarisation; this technique was used by several workers [22-25]. Handley et al. [23] noticed a lower resistivity of a copper fluidized-bed at higher frequencies. Abdallah [25] applied the impedancespectrum theory for fluidized-bed electrodes in the case of chain formation of the particles and gave extensive results for fluidized-gold-bed cells; in this experiment the impedance of the current collector or feeder is also taken into account. Calculations of the fluidized-bed resistivities by Fleischmann et al. $[26,27]$ based on charge transport during collisions scarcely agree with experimental results as found by Van Swaay, Beenackers and Welmers [28, 29], or by Sabacky and Evans [24].

In our study of suspension systems [30, 31], we have investigated the properties of conducting ceramic, graphite and metallic particles in aqueous $\mathrm{KOH}$ solutions up to high viscosity values, using the impedance technique with a four-electrode cell. The experimental results are compared with Bruggeman's symmetric and asymmetric theories and the GEM theory. Also 
Table 1. Overview of investigated material

\begin{tabular}{|c|c|c|c|}
\hline $\begin{array}{l}\text { Suspended } \\
\text { material }\end{array}$ & $\begin{array}{l}\text { Particle size } \\
2 a / \mu m\end{array}$ & $\begin{array}{l}\text { std. } \\
\text { dev./um }\end{array}$ & Supplier \\
\hline $\mathrm{B}_{4} \mathrm{C}$ & 70.7 & 31.7 & ESK, München \\
\hline $\mathrm{NbB}_{2}$ & 6.0 & 4.5 & HCSB, Berlin \\
\hline $\mathrm{NbC}$ & 6.7 & 4.2 & HCSB, Berlin \\
\hline $\mathrm{NbN}$ & 1.8 & 1.1 & HCSB, Berlin \\
\hline $\mathrm{TaC}$ & 1.2 & 0.69 & Ventron, Karlsruhe \\
\hline $\mathrm{TiN}$ & 6.8 & 3.6 & HCSB, Berlin \\
\hline $\mathrm{VC}$ & 3.3 & 1.8 & HCSB, Berlin \\
\hline VN & 5.5 & 1.1 & Cerac, Milwaukee \\
\hline $\mathrm{ZrC}$ & 1.6 & 1.1 & Ventron, Karlsruhe \\
\hline Graphite (ks 5-10) & 3.2 & 2.0 & Lonza, Basel \\
\hline Graphite (ks 25) & 6.6 & 4.2 & Lonza, Basel \\
\hline Graphite (ks 44) & 8.2 & 6.3 & Lonza, Basel \\
\hline Graphite (ks 10) & 9.3 & 4.2 & Lonza, Basel \\
\hline Graphite (ks 75) & 12.1 & 7.5 & Lonza, Basel \\
\hline Graphite (ks 75-5) & 28.9 & 22.5 & Lonza, Basel \\
\hline Zinc & 2.5 & 2.6 & Janssen, Geel \\
\hline Copper & 12.0 & 9.0 & Merck, Darmstadt \\
\hline Copper & 28.5 & 22.6 & Ridel de Haan, Hannover \\
\hline
\end{tabular}

the influence of flocculation and chain formation on the conductivity was studied. These instability aspects of suspensions are related to the attraction of the suspended particles by the Van der Waals-London dispersive forces and to electrostatic repulsion, as described in the Derjaguin-Landau-Verwey-Overbeek (DVLO) theory and its extensions [32, 34].

\section{Experimental details}

This investigation has been carried out with suspensions of metal carbide, nitride and boride particles as well as with graphite, zinc and copper particles. Suspensions were prepared in dilute $\left(10^{-3}, 10^{-2} \mathrm{M} \mathrm{KOH}\right)$ and concentrated $(2 \mathrm{M}, 12 \mathrm{M} \mathrm{KOH})$ solutions (Merck p.a.). After addition of a known amount of particles, the system was well mixed with a suspender under high-shear field conditions. Volume fractions up to high viscosities were prepared and studied. In the case of zinc in $2 \mathrm{M} \mathrm{KOH}$, at first $1 \mathrm{vol} \% \mathrm{~B}_{4} \mathrm{C}$ particles (supplied by Daiichi Kichenso Japan, particle size $1-1.5 \mu \mathrm{m}$ ) or $1 \mathrm{vol} \%$ Attagel 50 particles (supplied by MCA Zutphen NL, particle size $1 \mu \mathrm{m}$ ) were suspended in the system to prevent coagulation of the zinc particles; then a surfactant was added to inhibit corrosion of the zinc in the electrolyte and to improve the wetting of the particle surface; the amount of surfactant was proportional to the volume fraction of zinc $(0.58 \mathrm{ml}$ tertiary butyl ammonium hydroxide for $10 \mathrm{vol} \%$ zinc). The particle sizes with standard deviation (s.d.) were determined with a Leitz Aristomet microscope and Difa image-analysis apparatus. The results are given in Table 1 .

The impedance of the suspensions was measured as a function of the volume fraction particles using the four-electrode technique to avoid the influence of polarisation effects at the electrode surfaces. The measuring cell consisted of a Teflon tube with an internal diameter of $6 \mathrm{~mm}$ and a length of $150 \mathrm{~mm}$; on both ends a nylon socket with two platinum wire electrodes of $1 \mathrm{~mm}$ diameter each was mounted. These two wires were placed parallel with a separation of $5 \mathrm{~mm}$, perpendicular to the flow direction. To avoid precipitation, the suspension was pumped through the cell (about $20 \mathrm{~mm} / \mathrm{s}$ ) with a peristaltic pump. Also a heat exchanger, connected with a thermostat bath, was mounted in this circuit for temperature control at $25^{\circ} \mathrm{C}$

Figure 1 shows a block diagram of the electric and flow circuits of the impedance measurement system. An HP-86 microcomputer controlled the measurements. A signal amplitude of $100 \mathrm{mV}$ was applied with the Solartron- 1286 potentiostat. The data were directly printed, and stored on a magnetic disk for later plotting. The experiments in $10^{-3} \mathrm{M} \mathrm{KOH}$ and $10^{-2} \mathrm{M}$ $\mathrm{KOH}$ were carried out with a Solartron-1250 frequency analyser over a frequency range of $1-64 \mathrm{kHz}$ with repeated doubling of the frequency. For the electrolytes with ionic strength higher than $10^{-2} \mathrm{M}$, higher frequencies are required in order to scan the influence of the particle polarisation, and here a Solartron 1170 frequency response analyser with a frequency range of $1-500 \mathrm{kHz}$ was used. The cell was calibrated using literature values of the conductivities of the electrolytes [35]: $0.02687 \Omega^{-1} \mathrm{~m}^{-1}\left(10^{-3} \mathrm{M} \mathrm{KOH}\right), 0.2617 \Omega^{-1} \mathrm{~m}^{-1}$ $\left(10^{-2} \mathrm{M} \mathrm{KOH}\right)$ and $36.19 \Omega^{-1} \mathrm{~m}^{-1}(2 \mathrm{M} \mathrm{KOH})$. The particle conductivities of $\mathrm{B}_{4} \mathrm{C}$ and graphite were given by the supplier; the other values are from literature [36]. In Table 2 these data are summarized. In the last column of this table the dimensionless conductance $K_{\mathrm{d}}=\sigma_{\mathrm{d}} / \sigma_{\mathrm{c}}$ is also given, with $\sigma_{\mathrm{d}}$ the particle conductivity and $\sigma_{\mathrm{c}}$ the conductivity of the electrolyte. 


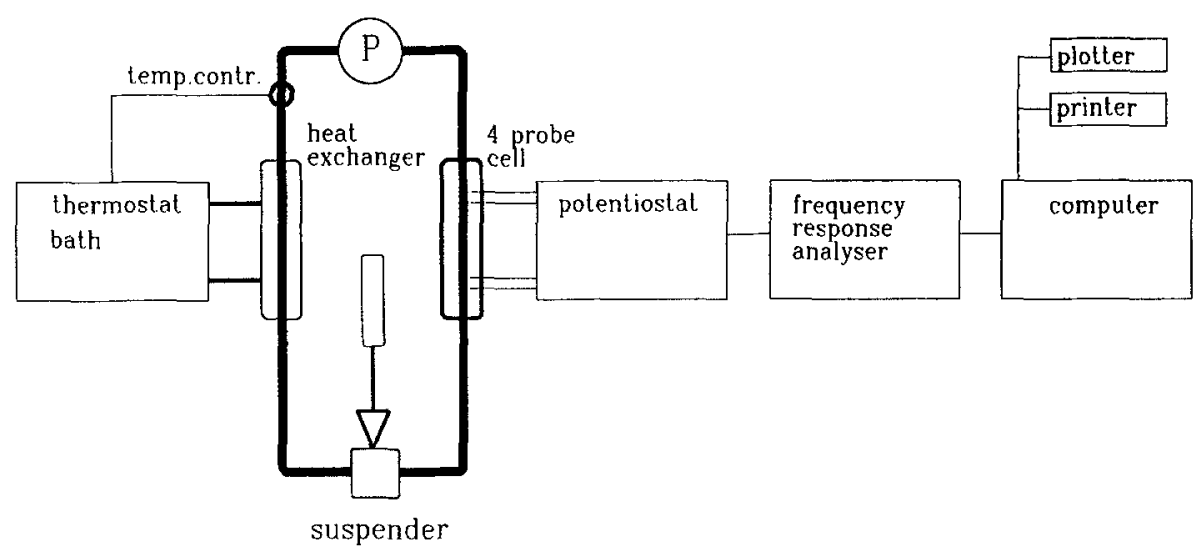

Fig. 1. Block diagram of the impedance measurement system. Thin lines: electric circuit; thick lines: flow circuit.

\section{Theory}

\subsection{Suspension properties}

The interaction potential of two suspended particles influences the suspension stability, that is the tendency of a suspension to remain dispersed and resist coagulation (see Fig. 2). The kinetics of coagulation is described in terms of the Derjaguin-Landau-VerweyOverbeek (DVLO) theory [32, 34]. Attraction between the particles is caused by the Van der Waals-London

Table 2. Conductivity of the particles, $\sigma_{d}$, and the (dimensionless) particle conductance, $K_{d}=\sigma_{d} / \sigma_{c}$, with $\sigma_{c}=$ the electrolyte conductivity

\begin{tabular}{llll}
\hline Suspended material & $\sigma_{d} / \mu \Omega^{-1} \mathrm{~m}^{-1}$ & $\begin{array}{l}\text { Concentration } \\
/ M \text { KOH }\end{array}$ \\
& \multicolumn{3}{l}{$K_{d}$} \\
\hline $\mathrm{B}_{4} \mathrm{C}$ & $4.5 \times 10^{-3}$ & $10^{-3}$ & $1.70 \times 10^{5}$ \\
$\mathrm{NbB}_{2}$ & 3.89 & $10^{-3}$ & $1.45 \times 10^{8}$ \\
$\mathrm{NbC}$ & 2.27 & $10^{-3}$ & $8.45 \times 10^{7}$ \\
$\mathrm{NbN}$ & 1.85 & $10^{-3}$ & $6.89 \times 10^{7}$ \\
$\mathrm{TaC}$ & 4.55 & $10^{-3}$ & $1.69 \times 10^{8}$ \\
TiN & 2.5 & $10^{-3}$ & $9.30 \times 10^{7}$ \\
$\mathrm{VC}$ & 1.28 & $10^{-3}$ & $4.76 \times 10^{7}$ \\
$\mathrm{VC}$ & 1.28 & 2 & $3.5 \times 10^{4}$ \\
$\mathrm{VN}$ & 1.67 & $10^{-2}$ & $6.22 \times 10^{7}$ \\
VN & 1.67 & 2 & $4.60 \times 10^{4}$ \\
ZrC & 0.65 & $10^{-3}$ & $2.42 \times 10^{7}$ \\
\hline Graphite (ks 5-10) & $1.04 \times 10^{-2}$ & $10^{-3}$ & $3.90 \times 10^{5}$ \\
Graphite (ks 5-10) & $1.04 \times 10^{-2}$ & $10^{-2}$ & $3.97 \times 10^{4}$ \\
Graphite (ks 25) & $1.04 \times 10^{-2}$ & $10^{-2}$ & $3.97 \times 10^{4}$ \\
Graphite (ks 44) & $1.04 \times 10^{-2}$ & $10^{-2}$ & $3.97 \times 10^{4}$ \\
Graphite (ks 10) & $1.04 \times 10^{-2}$ & $10^{-2}$ & $3.97 \times 10^{4}$ \\
Graphite (ks 75) & $1.04 \times 10^{-2}$ & $10^{-2}$ & $3.97 \times 10^{4}$ \\
Graphite (ks 75-5) & $1.04 \times 10^{-2}$ & 2 & $2.87 \times 10^{4}$ \\
\hline Zinc & 16.9 & $10^{-3}$ & $6.28 \times 10^{7}$ \\
Zinc (1\% B C) & 16.9 & 2 & $4.70 \times 10^{5}$ \\
Zinc (1\% B 4 C + S.) & 16.9 & 2 & $4.70 \times 10^{5}$ \\
Copper (M) & 59.8 & $10^{-3}$ & $2.23 \times 10^{9}$ \\
Copper (M) & 59.8 & $10^{-2}$ & $2.29 \times 10^{8}$ \\
Copper (RdH) & 59.8 & $10^{-3}$ & $2.23 \times 10^{9}$ \\
\hline
\end{tabular}

interaction energy, $V_{A}$, given by

$$
V_{A}=-\frac{A}{6}\left\{\frac{2}{r^{2}-4}+\frac{2}{r^{2}}+\ln \left(\frac{r^{2}-4}{r^{2}}\right)\right\}
$$

where $r=(2 a+h) / a$ is the dimensionless distance between the particles centres, $a$ the particle radius, $h$ the surface-to-surface separation and $A$ the Hamaker constant. At very short distances, $h$, this potential is approximated to

$$
V_{A} \simeq-\frac{A a}{12 h}
$$

Deviations from the Equations 1 and 2 can occur due to electromagnetic retardation effects in the Van der Waals-London interaction [32-34]. Electrostatic repulsion due to electric charges on the particle surfaces can prevent coagulation. For thin double layers (with the inverse dimensionless Debye-Hückel dis-

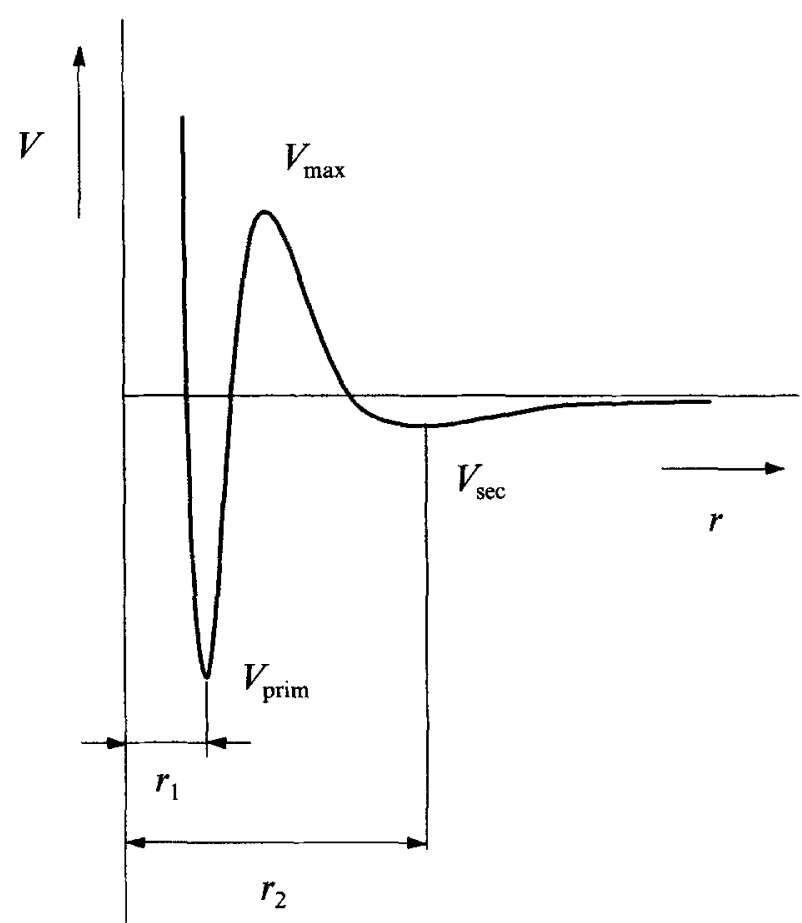

Fig. 2. Schematic representation of the interaction energy, $V$, as a function of the dimensionless distance, $r$, between two particle centres. 


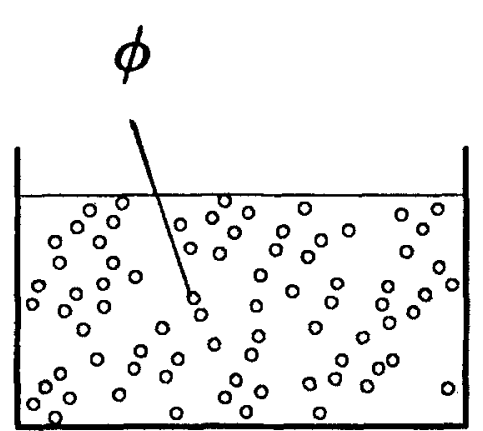

(a)

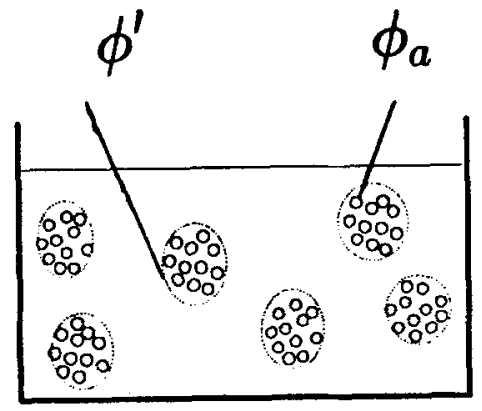

(b)

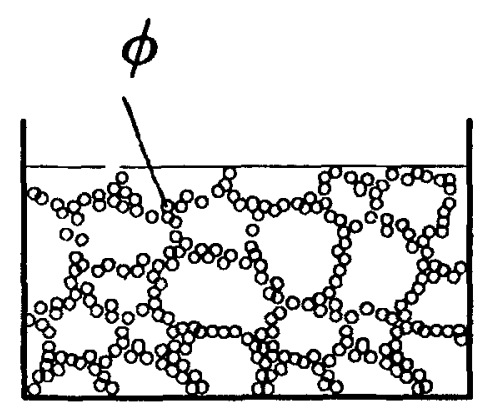

(c)

Fig. 3. Suspension models: $\phi$ is the volume fraction of the particles, $\phi^{\prime}$ is the volume fraction of agglomerates and $\phi_{\mathrm{a}}$ is the volume fraction of the particles in an agglomerate.

tance $\tau=a \kappa>10)$, low surface potentials $\left(e z_{i} \psi_{0}^{2} /\right.$ $k T<2)$ and symmetrical electrolytes [32] the repulsive energy $V_{\mathrm{R}}$ reads

$$
V_{\mathrm{R}}=2 \pi \varepsilon_{0} \varepsilon_{\mathrm{r}} a \psi_{0}^{2} \ln \left(1+\mathrm{e}^{-h \kappa}\right)
$$

where $\psi_{0}$ is the surface potential of the particles, $\varepsilon_{0}$ the dielectric constant in vacuum, $\varepsilon_{\mathrm{r}}$ the relative dielectric constant and $\kappa^{-1}$ is the Debye-Hückel double-layer thickness which depends on the ionic strength according to [37]

$$
\kappa^{2}=\frac{e^{2}}{\varepsilon_{0} \varepsilon_{\mathrm{r}} k T} \sum n_{i} z_{i}^{2}
$$

with $z_{i}$ and $n_{i}$ the charge numbers and the numbers of ions in the solution. Other repulsive potentials known to stabilize suspensions are based on steric hindrance [37] or on depletion [38]. These interactions are not considered here.

The interaction energy resulting from the potentials expressed in Equations 1 and 3 in general shows a deep primary minimum at $r_{1}$ and a secondary minimum at $r_{2}$ (Fig. 2). If the barrier $V_{\max }$ is small, $\sim 0(k T)$, primary coagulation can occur [39], leading to irreversible aggregation at a distance $r_{1}$. In the case of a deep secondary potential, $V_{\mathrm{sec}}$, and a high barrier, $V_{\max }$, the system shows secondary coagulation at the larger particle distance $r_{2}$; a shallow potential leads to reversible aggregation [39-41]. Reversibly aggregated networks easily break after shaking or pumping and a fluid system results (Bingham plastic behaviour). In the case of primary or secondary coagulation, chain

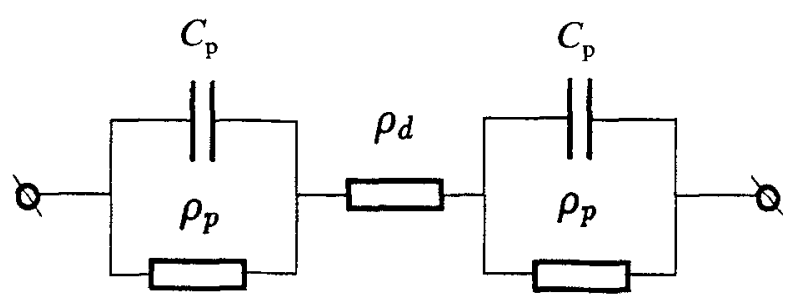

Fig. 4. Electric-equivalent scheme for a suspended particle. $C_{\mathrm{p}}$ is the double-layer capacity; $\rho_{p}$ is the polarisation resistivity and $\rho_{d}$ is the particle resistivity. formation or gelation of the suspension can occur, see Fig. 3c, resulting in three-dimensional structures $[39,40,42]$.

Hogg and Yang [41] calculated the coagulation rate for either primary or secondary coagulation and found in the latter case a weaker dependence on the electrolyte concentration; secondary coagulation is more important for larger particle sizes. This was also found by Zeichner and Schowalter [32, 34], who calculated stability ratios for primary and secondary coagulation taking into account hydrodynamic effects.

\subsection{Free particles}

The effective macroscopic conduction $\sigma_{\mathrm{m}}$ of a suspension containing a low volume fraction $\phi$ of identical spherical particles with a conductivity $\sigma_{\mathrm{d}}$ in a continuous phase of conductivity $\sigma_{\mathrm{c}}$ is given by Maxwell's relation [1-4]

$$
\frac{\sigma_{\mathrm{m}}-\sigma_{\mathrm{c}}}{\sigma_{\mathrm{m}}+2 \sigma_{\mathrm{c}}}=\phi \frac{\sigma_{\mathrm{d}}-\sigma_{\mathrm{c}}}{\sigma_{\mathrm{d}}+2 \sigma_{\mathrm{c}}}
$$

It remains valid at higher volume fractions in a meanfield approximation [43]. When a large sphere is added to a dilute dispersion containing much smaller particles, the disturbance of the electric field around the large sphere due to the small spheres may be neglected and the surroundings of this particle may then be considered as a new continuum. The asymmetric Bruggeman equation is found to hold for such a case [3-6].

$$
\frac{\left(\sigma_{\mathrm{d}}-\sigma_{\mathrm{m}}\right)^{3}}{\sigma_{\mathrm{m}}}=(1-\phi)^{3} \frac{\left(\sigma_{\mathrm{d}}-\sigma_{\mathrm{c}}\right)^{3}}{\sigma_{\mathrm{c}}}
$$

Introducing the dimensionless conductance $K_{\mathrm{m}}=\sigma_{\mathrm{m}} /$ $\sigma_{\mathrm{c}}$ for a suspension of spherical particles with a dimensionless conductance $K_{\mathrm{d}}=\sigma_{\mathrm{d}} / \sigma_{\mathrm{c}}$, we can write

$$
\frac{K_{\mathrm{d}}-K_{\mathrm{m}}}{K_{\mathrm{m}}^{1 / 3}\left(K_{\mathrm{d}}-1\right)}=1-\phi
$$

For nonconducting spherical particles $\left(\sigma_{d}=0\right)$, Equation 7 simplifies to

$$
K_{\mathrm{m}}=(1-\phi)^{3 / 2}
$$


This equation was proved to be valid by $\mathrm{De}$ La Rue et al. [3] for glass beads. For highly conducting spherical particles $\left(\sigma_{\mathrm{d}} \gg \sigma_{\mathrm{c}}, \sigma_{\mathrm{m}}\right)$ Equation 7 becomes

$$
K_{\mathrm{m}}=(1-\phi)^{-3}
$$

\subsection{Flocculated particles}

The asymmetric Bruggeman equation does not include the effects of flocculation or agglomerate formation due to the Van der Waals attraction. For particles in high electrolyte concentrations, the charge on the particle surface is compensated within a very short distance. Then the electrostatic repulsion between the particles is weak and flocculation can occur. The particle volume fraction, $\phi$, of a nonflocculated suspension, see Fig. 3a, is defined as

$$
\phi=\frac{V_{\mathrm{d}}}{V_{\mathrm{c}}+V_{\mathrm{d}}}=\frac{V_{\mathrm{d}}}{V_{\mathrm{t}}}
$$

where $V_{\mathrm{d}}$ is the total particle volume, $V_{\mathrm{c}}$ the volume of the continuous phase and $V_{1}$ the total volume. In the case of coagulation, see Fig. $3 \mathrm{~b}$, all particles are assumed to be present in agglomerates with a particle volume fraction $\phi_{\mathrm{a}}$ within each agglomerate.

$$
\phi_{\mathrm{a}}=\frac{V_{\mathrm{ad}}}{V_{\mathrm{ac}}+V_{\mathrm{ad}}}=\frac{V_{\mathrm{ad}}}{V_{\mathrm{a}}}
$$

$V_{\text {ad }}$ is the particle volume in the agglomerate, $V_{\text {ac }}$ is the liquid volume in the agglomerate and $V_{\mathrm{a}}$ is the total agglomerate volume. When the electric conductivity within the agglomerate is high, the conduction of the suspension is determined only by the volume fraction $\phi^{\prime}$ of the agglomerates. This gives, with the Equations 10 and 11 ,

$$
\phi^{\prime}=\frac{N V_{\mathrm{a}}}{V_{\mathrm{c}^{\prime}}+N V_{\mathrm{a}}}=\frac{N V_{\mathrm{a}}}{V_{\mathrm{t}}}=\frac{\phi}{\phi_{\mathrm{a}}}
$$

$N$ is the number of agglomerates and $V_{\mathrm{c}^{\prime}}$ the volume of the continuous phase in the case of agglomerate formation. In this model a constant value of $\phi_{a}$ is assumed, independent of the volume fraction of particles, and because $\phi_{\mathrm{a}}$ is always smaller than $1, \phi^{\prime}$ will be larger than $\phi$. In Equations 7 and 9, $\phi$ must be replaced by $\phi / \phi_{\mathrm{a}}$; furthermore $K_{\mathrm{d}}$, the conductance in the particle phase is supposed to decrease to $K_{\mathrm{a}}=\sigma_{\mathrm{a}} /$ $\sigma_{\mathrm{c}}$ (the agglomerate conductance):

$$
\frac{K_{\mathrm{a}}-K_{\mathrm{m}}}{K_{\mathrm{m}}^{1 / 3}\left(K_{\mathrm{a}}-1\right)}=\left(1-\phi / \phi_{\mathrm{a}}\right)
$$

and for highly conducting particles

$$
K_{\mathrm{m}}=\left(1-\phi / \phi_{\mathrm{a}}\right)^{-3}
$$

So it follows that coagulation results in an extra increase of $K_{\mathrm{m}}$ at equal volume fractions of conductive particles.

\subsection{Chain formation}

Some suspensions can form a three-dimensional structure (also called gel) as depicted in Fig. 3c. This gel formation depends on various parameters of the suspension such as the Hamaker constant, size and shape distribution, the surface charge and especially electrolyte concentration $[39,40]$. When electrostatic repulsion is not sufficient to overcome the Van der Waals attraction, bridging of particles is promoted. In the circumstance of flocculation, bridging is favored by an isotropic particle shape [40] or large particle size [41] and the electrostatic repulsion on the ends is somewhat weaker than on the side of the chain, as calculated by Thomas and McCorke [44]. Also the particle diffusion to the chain ends is larger than to the middle. Hence the chain grows anisotropically and can form a three dimensional structure, sometimes even at very low volume fractions. A direct result of such a network can be electronic conduction over long distances via the particle phase of conducting particles when the particle-particle contact resistance is low. A minimum volume fraction, called the percolation threshold, $\phi_{\mathrm{cr}}$, is required beyond which a strong increase in conductivity occurs due to these threedimensional networks. These suspensions are usually also good anti-settling systems. It was experimentally found $[14,16]$ that for $\sigma_{\mathrm{d}} \gg \sigma_{\mathrm{c}}$ the conductivity just above this threshold can be described by the scaling law

$$
\sigma_{\mathrm{m}} \sim\left(\phi-\phi_{\mathrm{cr}}\right)^{t}
$$

The exponent $(t)$ has been measured $[14,45]$ for a number of dispersions and has been found to be in the range $1.4-2.0$; the theoretical value is 2.0 . This scaling law is only valid for a small range of volume fractions above the percolation threshold.

The conductivity of suspensions in which percolation occurs may, away from the percolation threshold, be derived from Bruggeman's symmetric equation $[1,7]$ for spherical particles

$$
\phi_{\mathrm{c}} \frac{\sigma_{\mathrm{c}}-\sigma_{\mathrm{m}}}{\sigma_{\mathrm{c}}+2 \sigma_{\mathrm{m}}}+\phi_{\mathrm{d}} \frac{\sigma_{\mathrm{d}}-\sigma_{\mathrm{m}}}{\sigma_{\mathrm{d}}+2 \sigma_{\mathrm{m}}}=0
$$

For $\sigma_{\mathrm{c}} \ll \sigma_{\mathrm{d}}$ a percolation threshold occurs at $\phi \equiv$ $\phi_{\mathrm{d}}=1-\phi_{\mathrm{c}}=1 / 3$, and two cases can be distinguished: for $\phi<1 / 3, \sigma_{\mathrm{m}} \ll \sigma_{\mathrm{d}}$

$$
\sigma_{\mathrm{m}}=\sigma_{\mathrm{c}}(1-3 \phi)^{-1}
$$

and $\phi>1 / 3 ; \sigma_{\mathrm{c}} \ll \sigma_{\mathrm{m}}$

$$
\sigma_{\mathrm{m}}=\frac{3}{2} \sigma_{\mathrm{d}}\left(\phi-\frac{1}{3}\right)
$$

The percolation threshold actually depends on the depolarisation factor and hence on the shape of the dispersed particles. This results in $\phi_{\mathrm{cr}}=1 / 3$ for a spherical shape and goes to zero for highly anisotropic ellipsoids. Percolating systems with very low percolation thresholds have been found, e.g. by Michels and Brokken-Zijp [46, 47].

As discussed by McLachlan [8-10], the two Bruggeman equations describe two different kinds of suspension behaviour. Neither of these is capable of describing the experimentally observed percolation scaling law. Therefore, he developed the general 
effective-medium theory (GEM theory), which incorporates both Bruggeman's asymmetric and symmetric theory and the scaling law. After introduction of the critical volume fraction $\phi_{\mathrm{cr}}$ and the scaling exponent $t$ as parameters, the GEM equation for the conductivity becomes

$$
\begin{gathered}
\frac{\phi\left(\sigma_{\mathrm{d}}^{1 / t}-\sigma_{\mathrm{m}}^{1 / t}\right)}{\sigma_{\mathrm{d}}^{1 / t}+\left[\left(1-\phi_{\mathrm{cr}}\right) / \phi_{\mathrm{cr}}\right] \sigma_{\mathrm{m}}^{1 / t}} \\
+\frac{(1-\phi)\left(\sigma_{\mathrm{c}}^{1 / t}-\sigma_{\mathrm{m}}^{1 / t}\right)}{\sigma_{\mathrm{c}}^{1 / t}+\left[\left(1-\phi_{\mathrm{cr}}\right) / \phi_{\mathrm{cr}}\right] \sigma_{\mathrm{m}}^{1 / t}}=0
\end{gathered}
$$

It turns out that this equation is a very suitable expression to describe the conductivity of percolating and nonpercolating two-phase systems $[9,10]$.

\subsection{Particle-surface polarisation}

The conductivity of a suspension can be measured with the a.c. impedance technique. Due to the particleelectrolyte interface, this yields for the particle conduction a complex resistance $Z=Z^{\prime}+j Z^{\prime \prime}$. Hence, instead of a particle conductivity $\left(\sigma_{\mathrm{d}}\right)$, a complex conductivity, $\overline{\sigma_{d}(\omega)}$, is to be defined. It is assumed [22] that this impedance is the result of a series connection of the pure particle resistivity $\rho_{\mathrm{d}}=1 / \sigma_{\mathrm{d}}$ and twice a polarisation resistivity $\rho_{\mathrm{p}}=1 / \sigma_{\mathrm{p}}$ parallel with the double-layer capacity $C_{\mathrm{p}}$ (see Fig. 4). The impedance for one particle $\overline{\rho_{\mathrm{d}}(\omega)}$ is then

$\overline{\rho_{\mathrm{d}}(\omega)}=\rho_{\mathrm{d}}+\frac{2 \rho_{\mathrm{p}}}{1+\left(\omega / \omega_{0}\right)^{2}}+\mathrm{j} \frac{2 \rho_{\mathrm{p}} \omega / \omega_{0}}{1+\left(\omega / \omega_{0}\right)^{2}}$

where $\omega_{0}=1 / \rho_{\mathrm{d}} C_{\mathrm{d}}$. The polarisation resistivity $\left(\rho_{\mathrm{p}}\right)$ of a particle was calculated by Eardley $e t$ al. [22] and is given by

$$
\rho_{\mathrm{p}}=\frac{\mathscr{R} T}{n \mathscr{F} i_{0}} \frac{1}{a}
$$

where $\mathscr{R}$ is the molar gas constant, $T$ the absolute temperature, $n$ the number of electrons of the electrochemical reaction, $\mathscr{F}$ the Faraday constant, $i_{0}$ the exchange-current density and $a$ the particle radius.

Two frequency limits lead to a real resistivity of the suspension. At very low frequencies $\omega \ll \omega_{0}$, say $\omega \rightarrow 0$, the surface polarisation must be taken into account; then the dimensionless particle conduction becomes

$$
K_{\mathrm{d} 0}=\rho_{\mathrm{c}} / \lim _{\omega \rightarrow 0} \overline{\rho_{\mathrm{d}}(\omega)}=\rho_{\mathrm{c}} /\left(\rho_{\mathrm{d}}+2 \rho_{\mathrm{p}}\right)
$$

For high frequencies $\omega \gg \omega_{0}$, say $\omega \rightarrow \infty$, the surface polarisation resistance can be neglected and the conductance becomes

$$
K_{\mathrm{d} \infty}=\rho_{\mathrm{c}} / \lim _{\omega \rightarrow \infty} \overline{\rho_{\mathrm{d}}(\omega)}=\rho_{\mathrm{c}} / \rho_{\mathrm{d}}
$$

$K_{\mathrm{d} 0}$ and $K_{\mathrm{d} \infty}$ can be found by a fit of the experimental data with Equation 13 or 19. The microscopic polarisation resistivity can be derived with Equations 22 and 23, which gives

$$
\rho_{\mathrm{p}}=\frac{1}{2} \rho_{\mathrm{c}}\left(1 / K_{\mathrm{d} 0}-1 / K_{\mathrm{d} \infty}\right)
$$

If the suspension behaves as an agglomerated system, the measured macroscopic impedance is given by Equation 13 with limiting values $K_{\mathrm{m} 0}$ and $K_{\mathrm{m} \infty}$ defined analogous to Equations 22 and 23. The dimensionless macroscopic polarisation resistivity $R_{\mathrm{mp}}=\rho_{\mathrm{c}} / \rho_{\mathrm{mp}}$ is obtained from

$$
R_{\mathrm{mp}}=1 / K_{\mathrm{m} 0}-1 / K_{\mathrm{m} \infty}
$$

The microscopic particle polarisation parameter $\rho_{\mathrm{p}}$ (Equation 21) or $i_{0}$ can also be calculated from the slope of the function $R_{\mathrm{mp}}=f(\phi)$

$$
\frac{\mathrm{d} R_{\mathrm{mp}}}{\mathrm{d} \phi}=\frac{\mathrm{d}\left(1 / K_{\mathrm{m} \theta}\right)}{\mathrm{d} \phi}-\frac{\mathrm{d}\left(1 / K_{\mathrm{m} \infty}\right)}{\mathrm{d} \phi}
$$

Differentiating Equation 13 results in

$$
\begin{aligned}
\frac{\mathrm{d} R_{\mathrm{mp}}}{\mathrm{d} \phi}= & \frac{3}{\phi_{\mathrm{a}}}\left(1-\frac{\phi}{\phi_{\mathrm{a}}}\right)^{2}\left\{\frac{1}{\left(K_{\mathrm{d} 0}-1\right)\left(K_{\mathrm{d} 0}+2 K_{\mathrm{m} 0}\right) K_{\mathrm{m} 0}^{2 / 3}}\right. \\
& \left.-\frac{1}{\left(K_{\mathrm{d} \infty}-1\right)\left(K_{\mathrm{d} \infty}+2 K_{\mathrm{m} \infty}\right) K_{\mathrm{m} \infty}^{2 / 3}}\right\}
\end{aligned}
$$

For low volume fractions we have $K_{\mathrm{m} 0} \rightarrow 1$ and $K_{\mathrm{m} \infty} \rightarrow 1$, and Equation 27 reduces to

$$
\begin{aligned}
\left(\frac{\mathrm{d} R_{\mathrm{mp}}}{\mathrm{d} \phi}\right)_{\phi=0} & =\lim _{\phi \rightarrow 0}\left(\frac{\mathrm{d} R_{\mathrm{mp}}}{\mathrm{d} \phi}\right) \\
& =\frac{3}{\phi_{\mathrm{a}}}\left\{\frac{1}{\left(K_{\mathrm{d} 0}-1\right) K_{\mathrm{d} 0}}-\frac{1}{\left(K_{\mathrm{d} \infty}-1\right) K_{\mathrm{d} \infty}}\right\}
\end{aligned}
$$

With Equations 22 and 23 this leads to

$$
\left(\frac{\mathrm{d} R_{\mathrm{mp}}}{\mathrm{d} \phi}\right)_{\phi=0}=\frac{3}{\phi_{\mathrm{a}}}\left\{\frac{\rho_{\mathrm{d}}\left(\rho_{\mathrm{d}}+2 \rho_{\mathrm{p}}\right)}{\rho_{\mathrm{c}}\left(\rho_{\mathrm{d}}-\rho_{\mathrm{c}}\right)\left(\rho_{\mathrm{d}}+2 \rho_{\mathrm{p}}-\rho_{\mathrm{c}}\right)}\right\}
$$

Since $\rho_{\mathrm{p}} \propto 1 / i_{0}$, Equation 21, this slope is a function of the electrochemical exchange-current density.

\section{Results and discussion}

\subsection{Measurements of the conductance}

The impedance spectrum for different volume fractions of zinc particles, suspended in $10^{-3} \mathrm{M} \mathrm{KOH}$ is given in Fig. 5 and shows half circles which shift to lower resistances with increasing volume fractions of the particles. Results obtained for a graphite ks 10 suspension in $10^{-2} \mathrm{M} \mathrm{KOH}$, are seen in Fig. 6. Here also the half circles shift to lower resistances and become smaller with increasing volume fractions of the particles.

In the impedance spectrum of $\mathrm{B}_{4} \mathrm{C}$, suspended in $10^{-3} \mathrm{M} \mathrm{KOH}$, given in Fig. 7, the flattened half circles shift again to lower resistances; however, they become larger with increasing volume fractions of the particles. The behaviour shown in Figs 5-7 is characteristic for all of the suspensions in $10^{-3}$ and $10^{-2} \mathrm{M}$ $\mathrm{KOH}$.

The measurements in $2 \mathrm{M} \mathrm{KOH}$, where a frequency range up to $500 \mathrm{kHz}$ was used, show sometimes a 

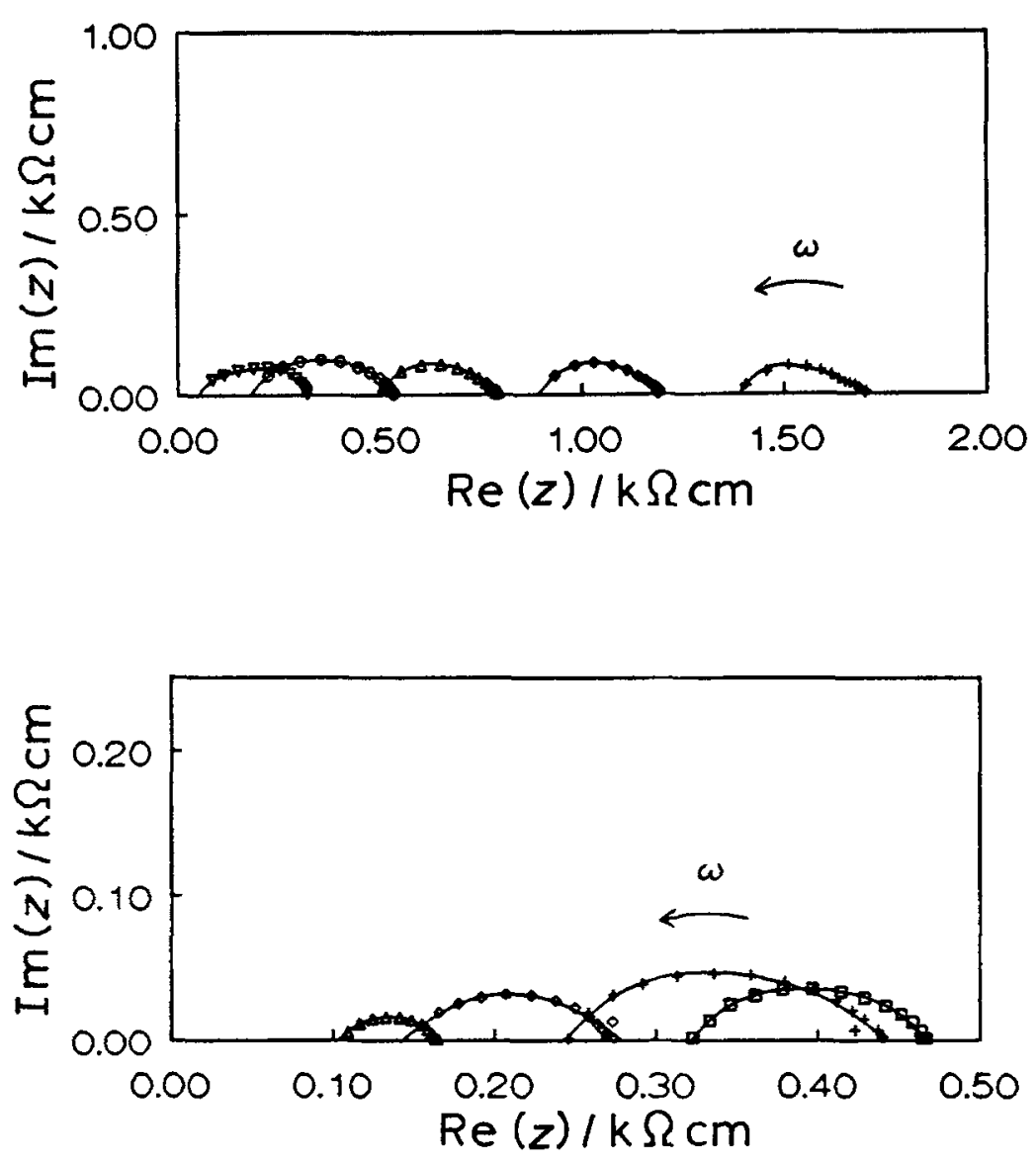

Fig. 5. Impedance spectrum for the zinc suspension in $10^{-3} \mathrm{M} \mathrm{KOH}$ at volume fractions, $\phi$, of $4 \%(\nabla), 6 \%(0), 10 \%(+), 18 \%(\Delta)$ and $44 \%(\bullet)$
Fig. 6. Impedance spectrum for the graphite ks 10 suspension in $10^{-2} \mathrm{M} \mathrm{KOH}$ at volume fractions, $\phi$, of: $1 \%(\square), 2 \%(+), 4 \%(\diamond)$, $6 \%(\Delta), 8 \%(0)$ and $10 \%(\nabla)$. second smaller half circle in the high frequency range, probably due to an increased conductance of the electrolyte at high frequencies due to the Wien effect. This was recently also observed by Ghowsi et al. [48].

From the impedance spectra, the real parts of the impedance at the high and low frequency limits were determined as function of the volume fraction of the particles. The results for zinc, graphite $\mathrm{ks} 10$ and $\mathrm{B}_{4} \mathrm{C}$ suspensions are expressed as conductances $\left(K_{\mathrm{m}}\right)$ in the Figs 8-10. Figures 11-13 show the $K_{\mathrm{m}}$ against $\phi$ curves for respectively suspensions of $\mathrm{NbB}_{2}, \mathrm{NbC}$ and copper (M). With increasing volume fraction, $\phi, K_{\mathrm{m} \infty}$ increases and $K_{\mathrm{m} 0}$ is nearly constant; only the graphite suspensions show an increase for $K_{\mathrm{m} 0}$.

\subsection{Comparison with the Bruggeman theories}

Considering the high conductance values, $K_{\mathrm{d}}$, of the particles investigated, it was expected that the experimental data could be fitted with Equation 9 or 14 for the asymmetric Bruggeman theory or with Equation 18 for the Bruggeman symmetric theory. However, it turned out by fitting the experimental conductivities that the resulting conductances of the agglomerate, $K_{\mathrm{a}}$, are much lower than the $K_{\mathrm{d}}$ values in Table 2 . Therefore subsequently the Bruggeman equations for moderate particle conductances, Equations 7 and 13, were used.

The parameters for an optimal fit of the data with

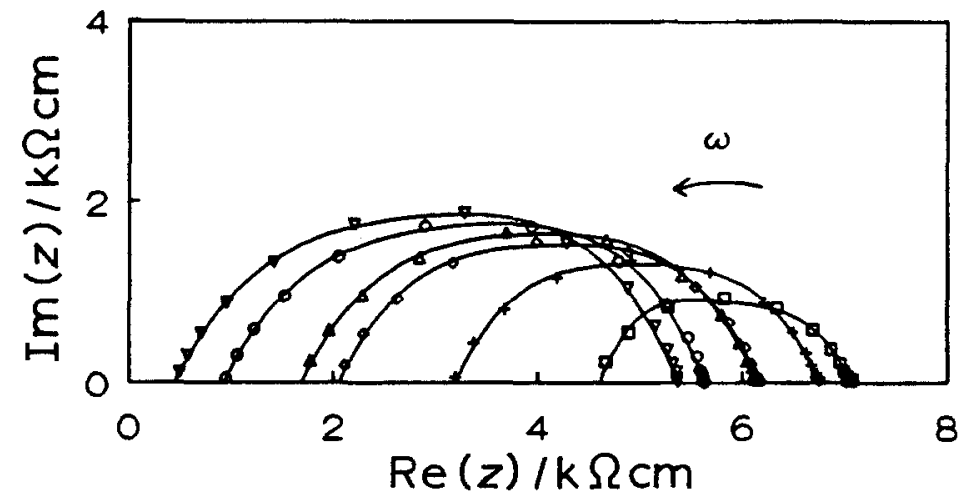

Fig. 7. Impedance spectrum for the $\mathrm{B}_{4} \mathrm{C}$ suspension in $10^{-3} \mathrm{M} \mathrm{KOH}$ at volume fractions, $\phi$, of: $6 \%(\square), 10 \%(+), 14 \%(\diamond), 16 \%(\Delta)$, $22 \%(0)$ and $30 \%(\nabla)$ 


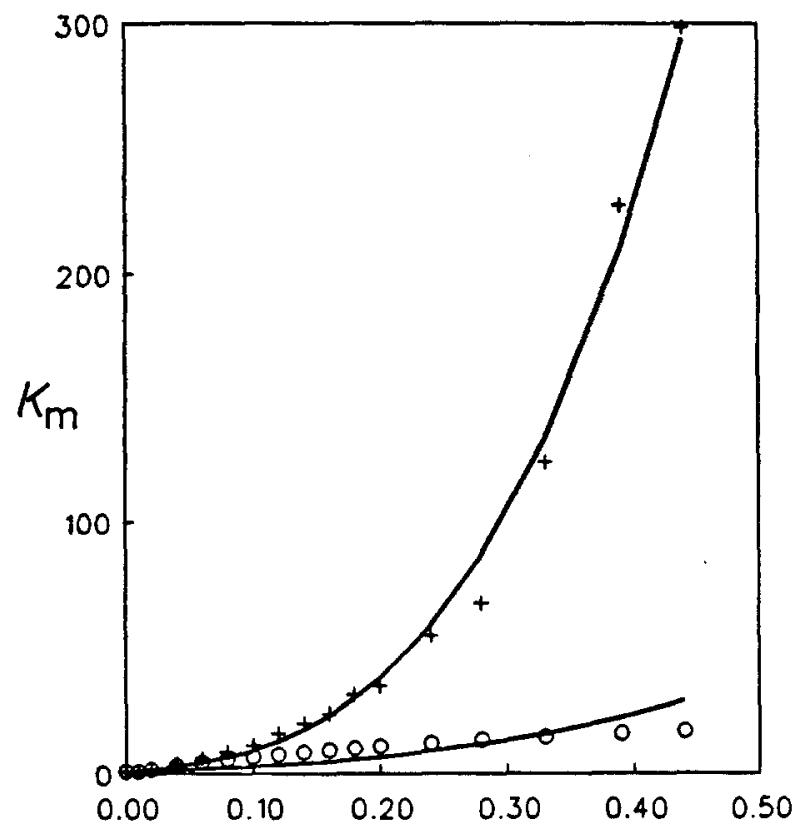

$\varphi$

Fig. 8. Conductances of the zinc suspension in $10^{-3} \mathrm{M} \mathrm{KOH}$ as function of the volume fraction, $\phi .(+)$ Conductance in the high frequency limit; $(0)$ conductance in the low frequency limit; lines are fitted with the GEM theory.

the asymmetric theory, were determined with the least-squares method. It appears that the asymmetric Bruggeman theory combined with flocculation, Equation 13, gives a good fit for the experimental results of suspensions which are given in Table 3. For the other suspensions the calculated $K_{\mathrm{a}}$ and $\phi_{\mathrm{a}}$ values were negative or imaginary, indicating a poor agreement of the model with the experimental results. Also solutions with $\phi_{\mathrm{a}}$ lower than the maximal value of $\phi$

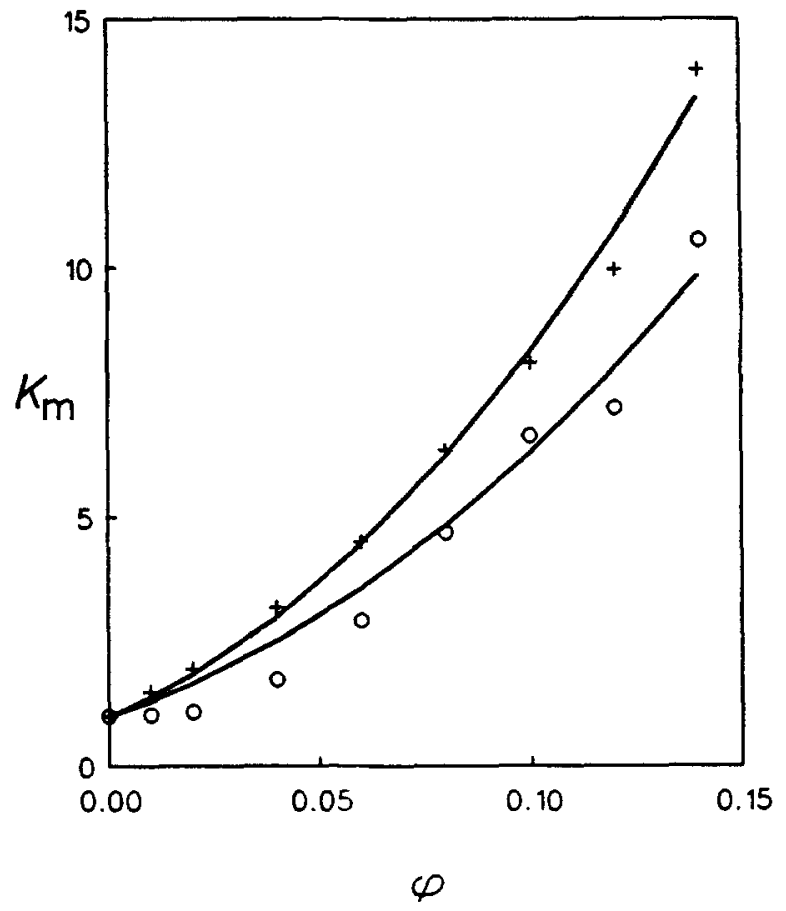

Fig. 9. Conductances of the graphite ks 10 suspension in $10^{-2} \mathrm{M}$ $\mathrm{KOH}$ as function of the volume fraction, $\phi ;(+)$ conductance in the high frequency limit; $(O)$ conductance in the low frequency limit; lines are fitted with the GEM theory.

and with a $K_{\mathrm{a}}$ lower than $K_{\mathrm{m}}$ were found, which have no physical meaning. From the data of the highfrequency limit the apparent agglomerate conductance $\left(K_{\mathrm{aco}}\right)$ and the volume fraction in the agglomerate $\left(\phi_{\mathrm{a}}\right)$ are obtained with Equation 13. These two values were then used for the calculation of the agglomerate conductances for the low frequency limit, $K_{\mathrm{a} 0}$. Results of these calculations are depicted as lines in Fig. 10 for $\mathrm{B}_{4} \mathrm{C}$. The corresponding parameters are summarised

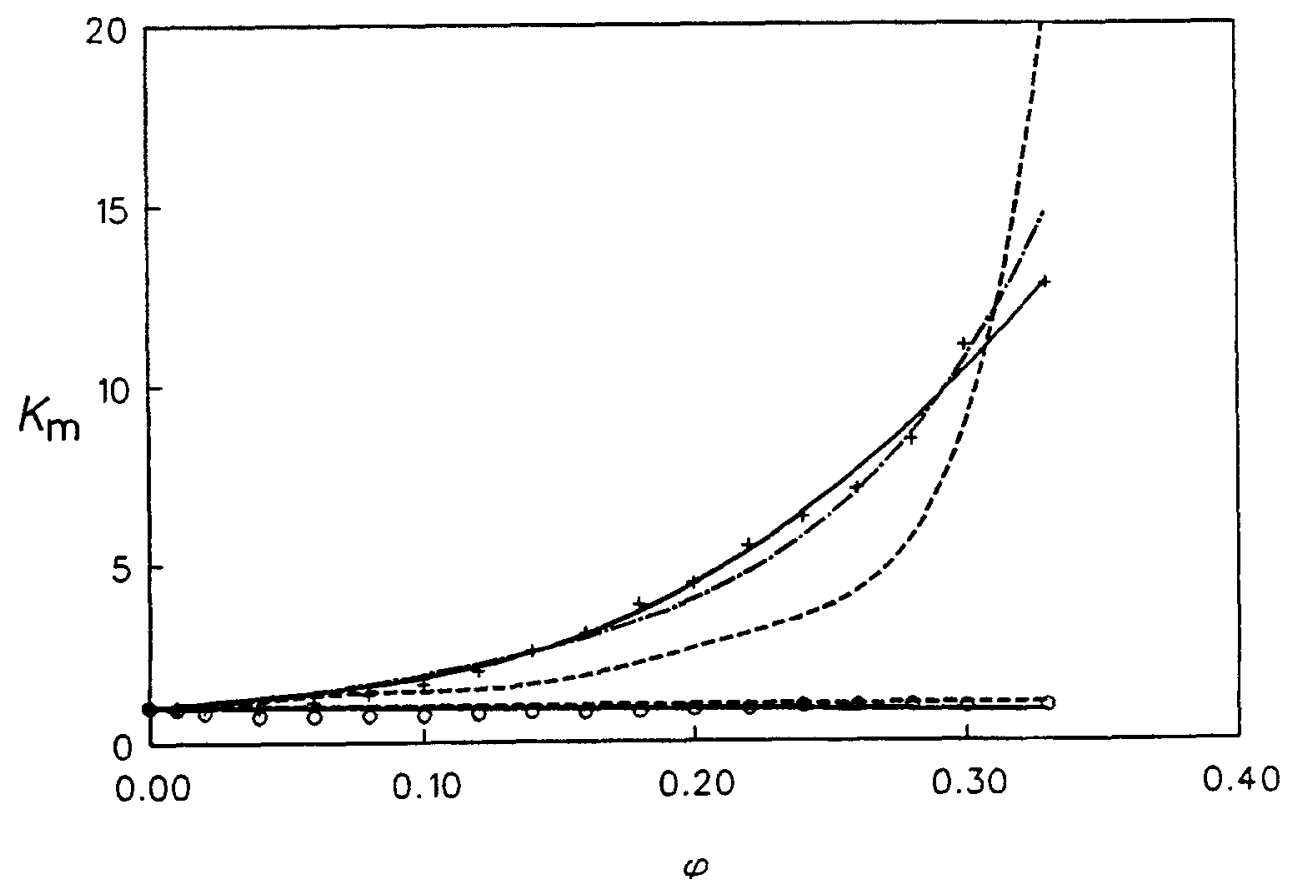

Fig. 10. Conductances of the $\mathrm{B}_{4} \mathrm{C}$ suspension in $10^{-3} \mathrm{M} \mathrm{KOH}$ as function of the volume fraction, $\phi ;(+)$ conductance in the high frequency limit; (O) conductance in the low frequency limit; (--) fit with the asymmetric Bruggeman theory; (--) fit with the symmetric Bruggeman theory; $(-)$ fit with the GEM theory. 
Table 3. Parameters for the best fit with the asymmetric theory of Bruggeman with flocculated particles. $\phi_{a}$ is the volume fraction of particles in an agglomerate, and $K_{a \infty 0}, K_{a 0}$ are the conductances at high and low frequencies, respectively, the variances of var. 1 and var. 2

\begin{tabular}{lllrrrr}
\hline $\begin{array}{l}\text { Suspended } \\
\text { material }\end{array}$ & $M$ KOH & $\phi_{a}$ & $K_{a \infty}$ & $K_{a 0}$ & var. 1 & var. 2 \\
\hline $\mathrm{B}_{4} \mathrm{C}$ & $10^{-3}$ & 0.52 & 123 & 0.8 & 0.13 & 0.15 \\
$\mathrm{NbB}_{2}$ & $10^{-3}$ & 0.47 & 64 & 1.7 & 0.12 & 0.21 \\
VC & $10^{-3}$ & 0.59 & 143 & 2.9 & 0.20 & 0.12 \\
ZrC & $10^{-3}$ & 0.59 & 18 & 1.7 & 0.07 & 0.09 \\
Graphite (ks 25) & $10^{-2}$ & 0.19 & 30 & 16 & 0.16 & 0.10 \\
Graphite (ks 75) & $10^{-2}$ & 0.33 & 82 & 17 & 0.11 & 0.89 \\
\hline
\end{tabular}

in Table 3, together with the parameters of the other suspensions for which also a good fit was obtained. In this table also the variances (var.) between measured and calculated points are given. Depending on the data sometimes a high correlation between $\phi_{\mathrm{a}}$ and $K_{\mathrm{a} \infty}$ was found; therefore the solutions found with the least squares method are not always unique, which raises doubt about the meaning of the values found for the parameters in this model.

From the values of $\phi_{\mathrm{a}}$ obtained it would follow that these particles in suspension behave as flocculated particles and not as free particles. The experimentally found agglomerate conductances, $K_{\mathrm{a} \infty}$, are much lower than the intrinsic conductivities of the particles in Table 2. A possible explanation of this discrepancy can be that between the flocculated particles a resistance, $R_{\mathrm{p}^{\prime}}$, arises caused by a constriction resistance, $R_{\text {con }}$, and a film resistance, $R_{\text {film }}$, between the flocculated particles. According to Holm [49], $R_{\mathrm{p}^{\prime}}$ can be expressed as

$$
\begin{aligned}
R_{\mathrm{p}^{\prime}} & =R_{\mathrm{con}}+R_{\mathrm{film}}, \quad R_{\mathrm{con}}=\frac{1}{4 \sigma_{\mathrm{d}} r_{\mathrm{ct}}}, \\
R_{\mathrm{film}} & =\frac{h}{\sigma_{\mathrm{c}} \pi r_{\mathrm{ct}}^{2}}
\end{aligned}
$$

where $r_{\mathrm{ct}}$ is the radius of the contact area of the particles. A good approximation for the conductivities [50] $\sigma_{\text {con }}$ and $\sigma_{\text {film }}$ is

$$
\sigma_{\mathrm{con}}=4 \sigma_{\mathrm{d}} \frac{r_{\mathrm{ct}}}{a}, \quad \sigma_{\mathrm{flm}}=\sigma_{\mathrm{c}} \frac{\pi r_{\mathrm{ct}}^{2}}{a h}
$$

For example, if the contact radius is $1 / 10$ of the particle radius $(1 \mu \mathrm{m})$, the particle distance, $h$, is $0.4 \mathrm{~nm}$ for primary flocculants and in the order of $50 \mathrm{~nm}$ for secondary flocculants; and we obtain $\sigma_{\mathrm{con}}=0.4 \sigma_{\mathrm{d}}$ and $\sigma_{\text {film }}=25 \sigma_{\mathrm{c}}$ (primary) or $\sigma_{\text {film }}=0.2 \sigma_{\mathrm{c}}$ (secondary). Since this resistance is placed in series with the particle resistance, especially the presence of the film will attribute to a very low conductivity of an agglomerate. This can explain the differences between $K_{\mathrm{d}}$ and $K_{\mathrm{a} \infty}$. Furthermore, a poor wetting of the particle surface can also influence $\sigma_{\text {film }}$

Comparison of the particle conductances in Table 3 shows also a much lower value for the lower frequency limit, $K_{\mathrm{a} 0}$. This points at a strong influence of the particle-surface polarisation.

Fitting of the $\mathrm{B}_{4} \mathrm{C}$ data with the symmetric theory of Bruggeman, Equation 16, with the optimal value of $K_{\mathrm{a} \infty}=1000$ and $K_{\mathrm{a} 0}=1.5$, does not result in a good fit (Fig. 10). For the conductance of the two zinc suspensions in $2 \mathrm{M} \mathrm{KOH}$, Equation 7 for free particles

\begin{tabular}{|c|c|c|c|c|c|c|c|}
\hline $\begin{array}{l}\text { Suspended } \\
\text { material }\end{array}$ & $M K O H$ & $t$ & $\phi_{c r}$ & $K_{d \infty}^{\prime}$ & $K_{d 0}^{\prime}$ & var. 1 & var. 2 \\
\hline $\mathrm{B}_{4} \mathrm{C}$ & $10^{-3}$ & 1.15 & 0.21 & 85 & 0.6 & 0.06 & 0.15 \\
\hline $\mathrm{NbB}_{2}$ & $10^{-3}$ & 1.15 & 0.17 & 73 & 3.2 & 0.08 & 0.19 \\
\hline $\mathrm{NbC}$ & $10^{-3}$ & 0.72 & 0.05 & 23 & 13.4 & 0.03 & 0.07 \\
\hline $\mathrm{NbN}$ & $10^{-3}$ & 0.25 & 0.17 & 8.1 & 0.5 & 0.19 & 0.40 \\
\hline $\mathrm{TaC}$ & $10^{-3}$ & 0.45 & 0.11 & 9.4 & 4.3 & 0.05 & 0.07 \\
\hline $\mathrm{TiN}$ & $10^{-3}$ & 0.92 & 0.04 & 65 & 35 & 0.04 & 0.13 \\
\hline VC & $10^{-3}$ & 1.42 & 0.27 & 149 & 5.3 & 0.20 & 0.13 \\
\hline VN & $10^{-2}$ & 0.90 & 0.22 & 49 & 0.5 & 0.16 & 0.22 \\
\hline $\mathrm{ZrC}$ & $10^{-3}$ & 1.55 & 0.28 & 49 & 2.5 & 0.06 & 0.08 \\
\hline Graphite (ks 5-10) & $10^{-3}$ & 1.60 & 0.01 & 3090 & 2960 & 0.03 & 0.04 \\
\hline Graphite (ks 5-10) & $10^{-2}$ & 1.70 & 0.09 & 1970 & 1710 & 0.28 & 0.36 \\
\hline Graphite (ks 25) & $10^{-2}$ & 1.80 & 0.09 & 830 & 430 & 0.21 & 0.14 \\
\hline Graphite (ks 44) & $10^{-2}$ & 3.00 & 0.11 & 2460 & 1290 & 0.09 & 0.24 \\
\hline Graphite (ks 10) & $10^{-2}$ & 2.10 & 0.002 & 460 & 300 & 0.06 & 0.13 \\
\hline Graphite (ks 75) & $10^{-2}$ & 1.60 & 0.17 & 480 & 300 & 0.11 & 0.33 \\
\hline Copper (M) & $10^{-3}$ & 0.30 & 0.11 & 10 & 0.7 & 0.06 & 0.22 \\
\hline Copper (M) & $10^{-2}$ & 0.18 & 0.14 & 5.4 & 0.7 & 0.07 & 0.40 \\
\hline Copper (RdH) & $10^{-3}$ & 0.38 & 0.08 & 12 & 0.8 & 0.11 & 0.35 \\
\hline Zinc & $10^{-3}$ & 3.55 & 0.003 & 3580 & 230 & 0.13 & 0.60 \\
\hline
\end{tabular}
had to be used and the calculations are based on this

Table 4. Parameters of the GEM model for particles suspended in electrolytes of low ionic strength 
Table 5. Parameters of the GEM model for particles suspended in electrolytes with high ionic strength

\begin{tabular}{llllllll}
\hline Suspendend material & $M$ KOH & $t$ & $\phi_{c r}$ & $K_{d \infty 0}^{\prime}$ & $K_{a 0}^{\prime}$ & var. 1 & var. 2 \\
\hline VC & 2 & 2.10 & 0.40 & $3 \times 10^{-3}$ & $1 \times 10^{-3}$ & 0.01 & 0.26 \\
VN & 2 & 0.18 & 0.20 & 2.6 & 0.7 & 0.02 & 0.20 \\
\hline Graphite (ks 5-75) & 2 & 0.5 & 0.04 & 5.7 & 0.8 & 0.06 & 0.77 \\
\hline Zinc (1\% B C) & 2 & 0.20 & 0.33 & 5.5 & 0.5 & 0.12 & 0.37 \\
Zinc (1\% B C + S.) & 2 & 1.20 & 0.44 & 59 & 7.0 & 0.04 & 0.65 \\
Zinc (1\% At.) & 2 & 0.50 & 0.07 & 3.5 & 0.8 & 0.03 & 0.02 \\
Zinc (1\% At.) & 12 & 0.40 & 0.18 & 11 & 0.8 & 0.06 & 0.07 \\
Zinc (1\% At. + 0.5 M ZnO) & 12 & 1.10 & 0.013 & 31 & 16 & 0.10 & 0.25 \\
\hline
\end{tabular}

equation. So it is assumed that addition of $B_{4} C$ particles to this suspension prevents flocculation. An addition of a surfactant results here in a higher value of $K_{\mathrm{a} 0}$ and a lower polarisation resistance of the particles, i.e. an increase of the exchange-current density $i_{0}$.

\subsection{Comparison with the GEM theory}

Next the optimal fit for the experimental conductances with the GEM model, Equation 19, was determined, using the same procedure as before. The calculated parameters of Equation 19 are given in Table 4 for the suspensions at low ionic strength and in Table 5 for the suspensions at high ionic strength. Comparing the variances for the GEM theory and the Bruggeman theory, Table 3 shows in general a lower value for the GEM model and thus a better fit of the experimental data. An example of a fit with the GEM

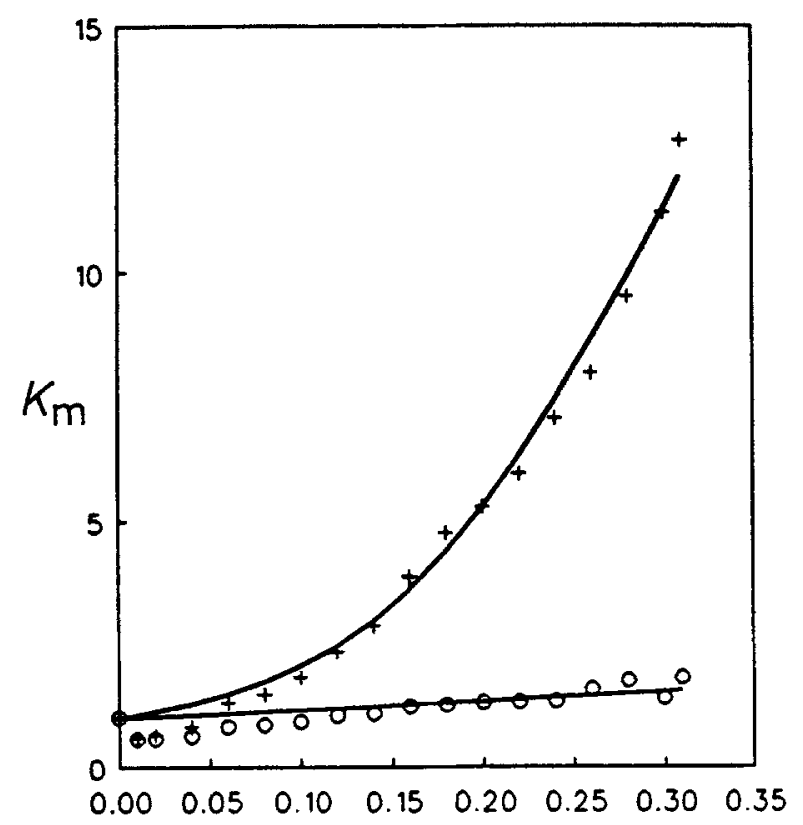

$\varphi$

Fig. 11. Conductances of the $\mathrm{NbB}_{2}$ suspension in $10^{-3} \mathrm{M} \mathrm{KOH}$ as function of the volume fraction, $\phi .(+)$ Conductance in the high frequency limit; $(O)$ conductance in the low frequency limit. Lines are calculated with the GEM theory. theory compared with the Bruggeman fit is seen in Fig. 10.

Results of the calculations with the GEM theory are depicted as full lines in Figs 8-13 for, successively, the suspensions of zinc, graphite ks $10, \mathrm{~B}_{4} \mathrm{C}, \mathrm{NbB}_{2}, \mathrm{NbC}$ and copper (M) in $10^{-3} \mathrm{M} \mathrm{KOH}$. A result at high ionic strength is presented in Fig. 14 for a suspension of zinc in $2 \mathrm{M} \mathrm{KOH}$ with addition of $1 \% \mathrm{~B}_{4} \mathrm{C}$ and a surfactant.

Most of the conductance data of the suspensions agree very well with calculations with the GEM model. As in the case of the Bruggeman fit, a large difference between $K_{\mathrm{d}}$ and $K_{\mathrm{d} \infty}^{\prime}$ is found, which again can be explained by the film resistance between the particles and the poor wetting of the particle surface.

The $\mathrm{NbC}$ data (Fig. 12) indicate a slower increase with the volume fraction at higher $\phi$ which influences the fit with the GEM equation. This effect was also found for the TiN suspension. The conductance at the

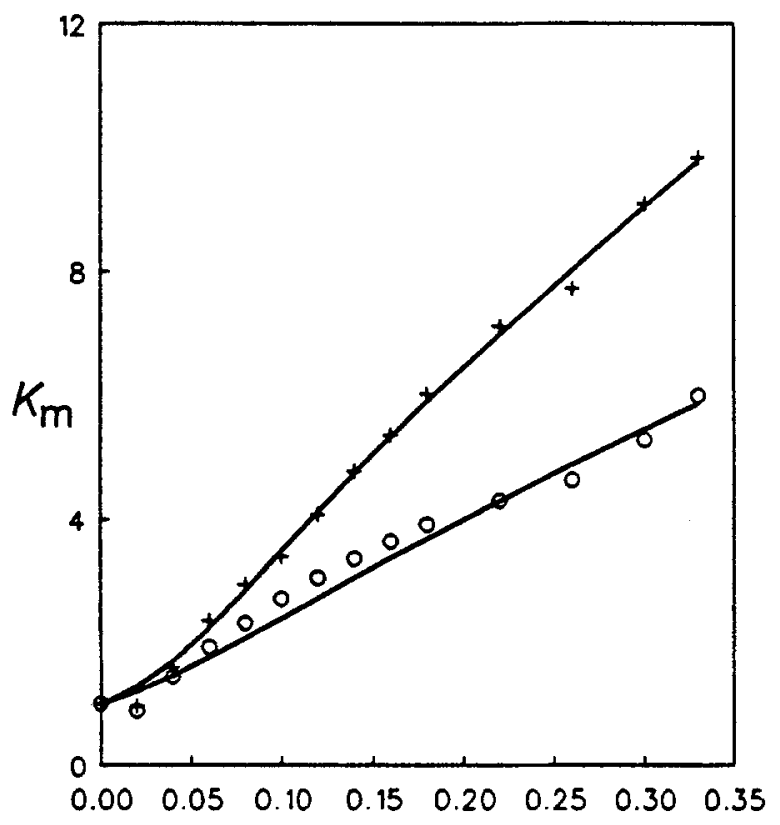

$\infty$

Fig. 12. Conductances of the $\mathrm{NbC}$ suspension in $10^{-3} \mathrm{M} \mathrm{KOH}$ as function of the volume fraction, $\phi .(+)$ Conductance in the high frequency limit; $(O)$ conductance in the low frequency limit. Lines are calculated with the GEM theory. 


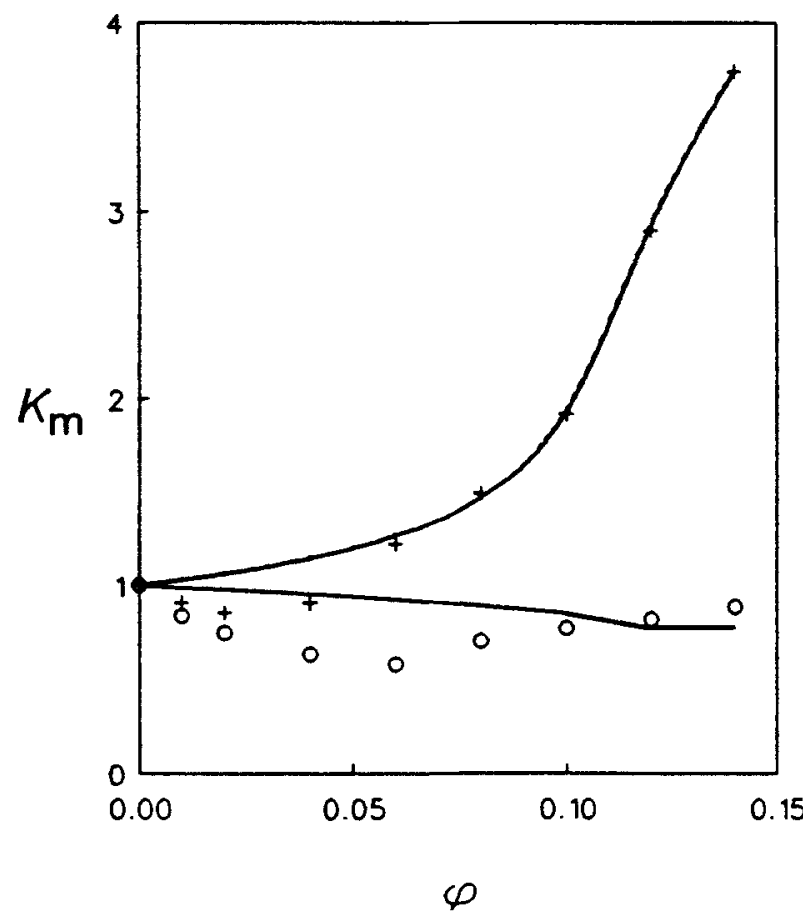

Fig. 13. Conductances of the copper (M) suspension in $10^{-3} \mathrm{M}$ $\mathrm{KOH}$ as function of the volume fraction, $\phi .(+)$ Conductance in the high frequency limit; $(0)$ conductance in the low frequency limit. Lines are calculated with the GEM theory.

low-frequency limit of the zinc suspensions in $2 \mathrm{M}$ $\mathrm{KOH}$, with $1 \% \mathrm{~B}_{4} \mathrm{C}$ and surfactant, as given in Fig. 14, shows also a remarkable behaviour with increasing volume fraction: first a decrease and then an increase is noticed. It appears that at low volume fractions of the particles, polarisation resistance dominates; however, above a certain volume fraction the percolation threshold is reached which determines the

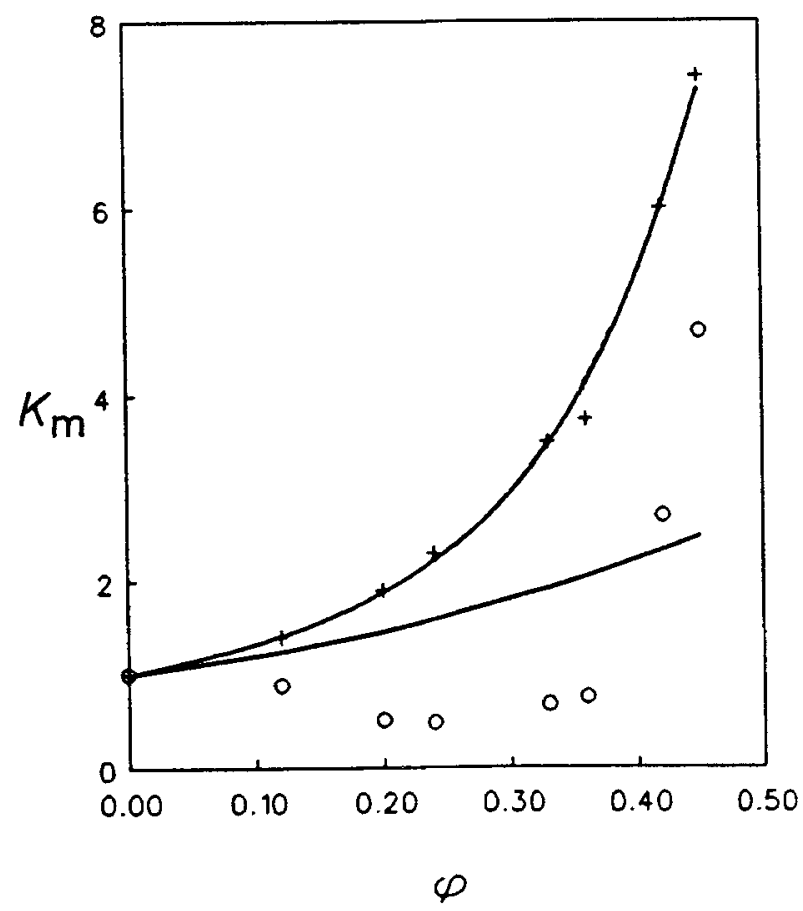

Fig. 14. Conductances of the zinc $\left(+1 \% \mathrm{~B}_{4} \mathrm{C}+\right.$ surfactant $)$ suspension in $2 \mathrm{M} \mathrm{KOH}$ as function of the volume fraction, $\phi$. $(+)$ Conductance in the high frequency limit; $(O)$ conductance in the low frequency limit. Lines are calculated with the GEM theory.

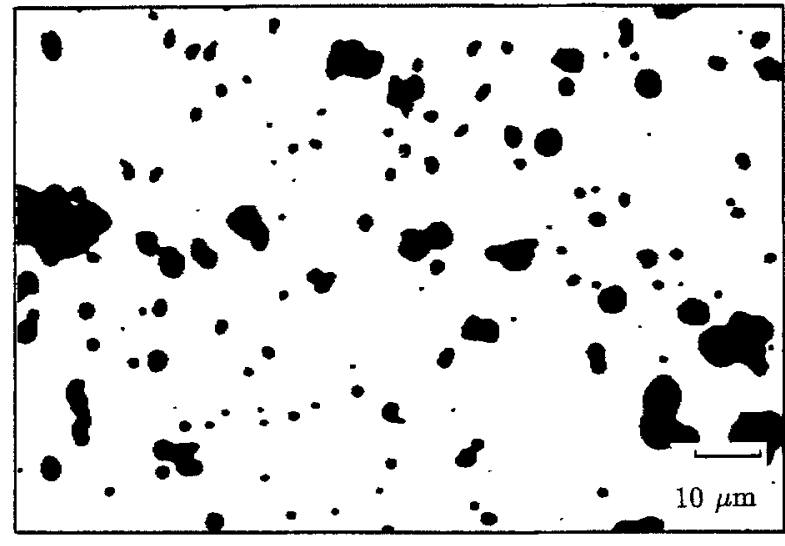

Fig. 15. Microscope picture of the zinc suspension of about $0.5 \mathrm{vol} \%$ in $10^{-3} \mathrm{M} \mathrm{KOH}$.

conductivity. In this case, neither the Bruggeman nor the GEM theory gave a good fit. The addition of surfactant shows an increase of $\phi_{\mathrm{cr}}$ and of both $K_{\mathrm{d}}^{\prime}$ values compared with the zinc suspension without surfactant (Table 4). The increase of $\phi_{c r}$, i.e. of a higher volume fraction where percolation occurs, indicates the disperging action of the surfactant. Furthermore, it appears that addition of the surfactant results in a better wetting of the particle surface and therefore of higher $K_{d}^{\prime}$ values.

It is expected that at low $\phi_{\mathrm{cr}}$ values percolation (chain formation) occurs, which results in a high conductance at the both frequency limits, as follows from $K_{\mathrm{d}}^{\prime}$ in Table 4. Furthermore a high $K_{\mathrm{d}}^{\prime}$ value results in an increase of $t$. Figure 15 shows a microscopic view of the zinc suspension. As can be noticed, the zinc particles with an arbitrary shape, are partially flocculated and no chain formation is observed. Yet with the GEM theory a value of $\phi_{\mathrm{cr}}=0.003$ was found, which points at chain formation at very low values of the volume fraction. The graphite ks 5-10 suspension in $10^{-3} \mathrm{M} \mathrm{KOH}$ shows a somewhat increased value of $\phi_{\text {cr }}=0.01$. The microscopical view of Fig. 16 indi-

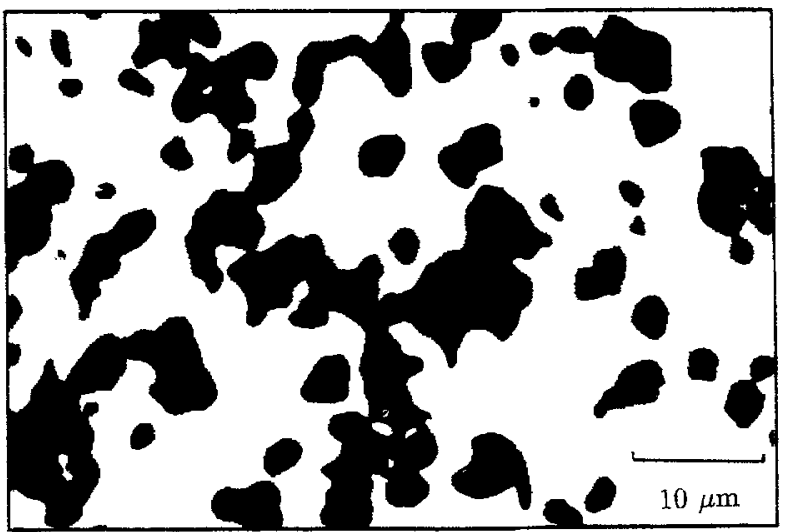

Fig. 16. Microscope picture of the graphite ks 5 suspension of about $0.5 \mathrm{vol} \%$ in $10^{-3} \mathrm{M} \mathrm{KOH}$. 


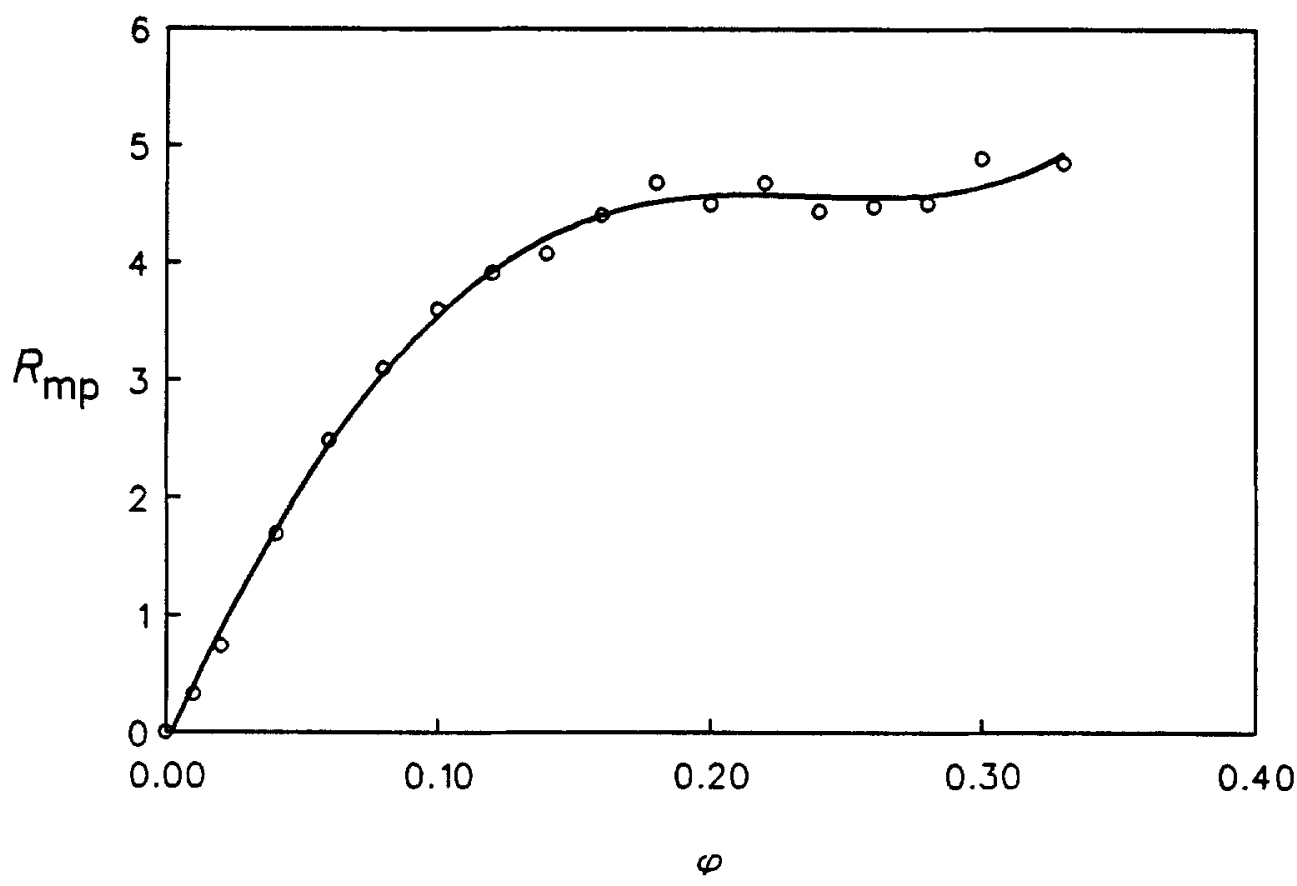

Fig. 17. Polarisation resistivity of the $\mathrm{B}_{4} \mathrm{C}$ suspension as function of the volume fraction.

cates however chain formation of graphite particles with arbitrary shape; therefore a lower percolation threshold $\phi_{\mathrm{cr}}$ was expected. It is also noticed that the percolation threshold, as found for both the zinc and graphite suspension, is lower than the true value because other pictures like Fig. 15 and Fig. 16 show at lower volume fraction negligible chain formation. A certain deviation can occur by correlation effects between the parameters. This casts doubt on the precise interpretation of the fitted values of $\phi_{\mathrm{cr}}$ as a percolation threshold.

Increasing ionic strength for the graphite ks 5-10, copper, $\mathrm{VC}, \mathrm{VN}$ and zinc suspensions shows a decrease of $K_{\mathrm{d}}^{\prime}$ and an increase of $\phi_{\mathrm{cr}}$ (Table 4 and Table 5).
Most suspensions in electrolytes with high ionic strength as given in Table 5, show $K_{\mathrm{d} 0}^{\prime}$ values lower than 1 . Only the zinc suspension in $12 \mathrm{M} \mathrm{KOH}+0.5 \mathrm{M}$ $\mathrm{ZnO}$ shows a higher $K_{\mathrm{d} 0}^{\prime}$, which indicates a decrease of the polarisation resistance due to the addition of the electrochemically active $\mathrm{ZnO}$.

The results of $\mathrm{VC}$ in this table show a value lower than 1 for both $K_{\mathrm{d}}^{\prime}$. This was also found for $\mathrm{NbC}, \mathrm{ZrC}$ and graphite ks 5 in $2 \mathrm{M} \mathrm{KOH}$; the data of these last measurements are not included in Table 5. These lower conductances of suspensions in $2 \mathrm{M} \mathrm{KOH}$ are probably caused by an increased surface tension for a higher $\mathrm{KOH}$ concentration [51], resulting in a poorer wetting of the particle surface. The higher conduc-

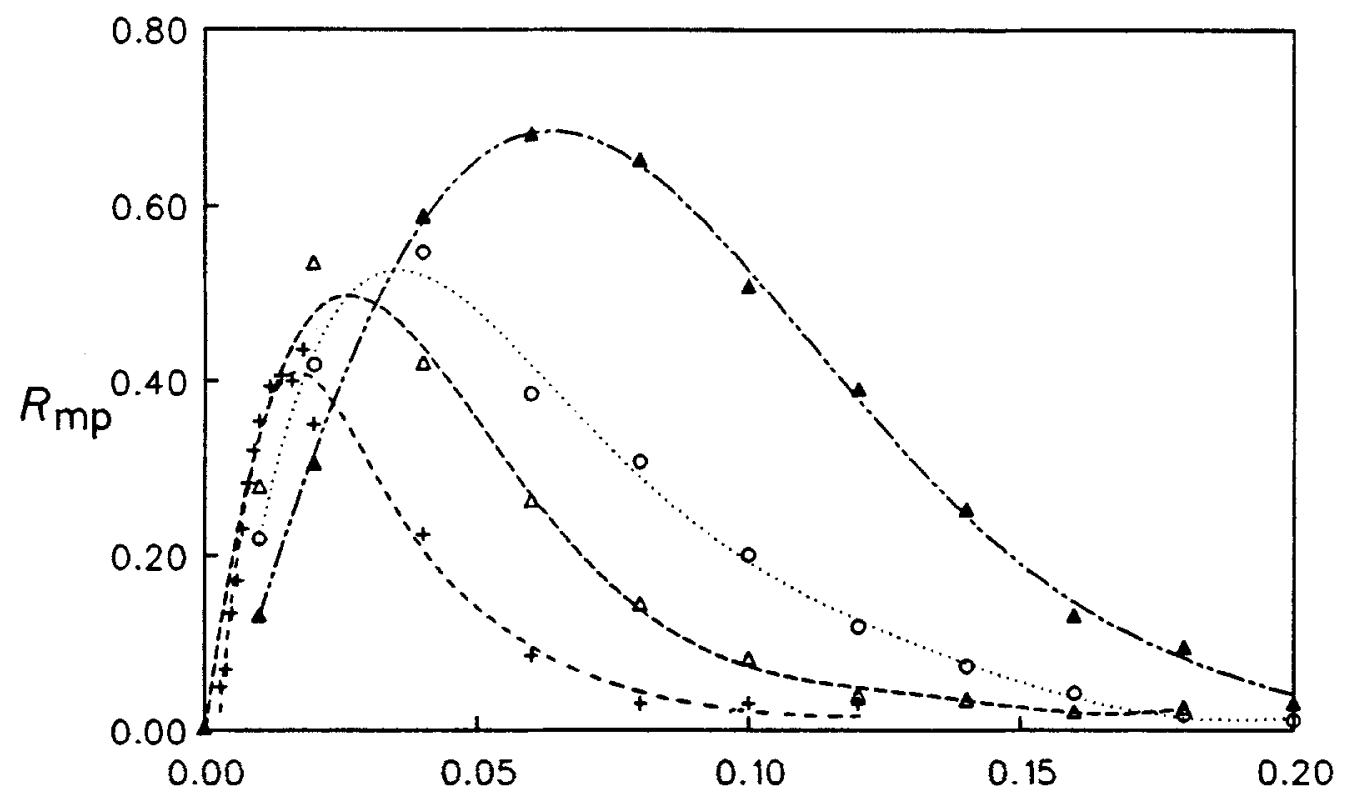

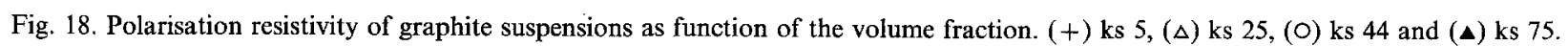


tances for the larger graphite particles (ks 75-5) can be explained by a possibly better wetting of particles with increased radii. The increased conductances for a zinc suspension in $2 \mathrm{M} \mathrm{KOH}$, when a surfactant is added, supports this assumption. Poor wetting of the suspended particles can, like the film resistance, explain the lower $K_{\mathrm{d} \infty}^{\prime}$ value compared with $K_{\mathrm{d}}$ as given in Table 2.

\subsection{Particle-surface polarisation}

From experimental data of $K_{\mathrm{d} \infty}^{\prime}$ and $K_{\mathrm{d} 0}^{\prime}$ the polarisation resistivity, $R_{\mathrm{mp}}$, is obtained as a function of $\phi$; this is given in Fig. 17 for the $\mathrm{B}_{4} \mathrm{C}$ suspension. The polarisation resistivity for the $\mathrm{ZrC}$ suspension shows a maximum and is lower than for the $\mathrm{B}_{4} \mathrm{C}$ suspension. For the graphite suspensions in $2 \mathrm{M} \mathrm{KOH}$ the polarisation resistivity, as function of the volume fraction, is given in Fig. 18 for different particle sizes (ks 5, ks 25, ks 44 and ks 75); at higher volume fractions the polarisation resistivity, $R_{\mathrm{p}}$, becomes lower. An increase in the value $\phi_{\max }$ (where $R_{\mathrm{mp}}$ is maximal) with the particle size is noticed for the graphite suspensions (except graphite ks 10); this can be due to a smaller polarisation resistivity with increasing particle size, $c f$. Equation 21. The sharp decrease after a maximum of $R_{\mathrm{pm}}$ can be attributed to short-circuiting of the microscopic polarisation resistances by chain forma- tion of the particles. It is assumed, that chain formation becomes dominating at the maximum of the function $R_{\mathrm{mp}}=f(\phi)$. This effect of short-circuiting of the double-layer capacity was also noticed for the suspension of $\mathrm{ZrC}$, both zinc suspensions in $2 \mathrm{M} \mathrm{KOH}$ with $1 \% \mathrm{~B}_{4} \mathrm{C}$ and the zinc suspension with $1 \%$ Attagel in $12 \mathrm{M} \mathrm{KOH}+0.5 \mathrm{M} \mathrm{ZnO}$ at much higher volume fractions. The volume fractions, $\phi_{\max }$, at the maximum of $R_{\mathrm{mp}}$, are given in Table 6 .

No maximum in the $R_{\mathrm{mp}}$ against $\phi$ curves was found for the $\mathrm{NbC}, \mathrm{TaC}, \mathrm{TiN}$, zinc $\left(10^{-3} \mathrm{M} \mathrm{KOH}\right)$ and copper $(\mathrm{RdH})$ suspensions, in spite of a low $\phi_{\mathrm{cr}}$ value. These results reveal, however, in most cases a $K_{\mathrm{d} 0}^{\prime}$ value greater than 1 . Therefore, it must be concluded that chain formation not always leads to a decrease of the polarisation resistivity. In Table 6 also the values of $\phi_{\mathrm{a}}$ and $\phi_{\mathrm{cr}}$, as found with the two models used before, are compared with $\phi_{\max }$. These three values differ, but a similar trend between the three values can be noticed, which indicates that $\phi_{\mathrm{cr}}$, found with the GEM theory, is physically meaningful.

The slope of the dimensionless polarisation parameter, $\mathrm{d} R_{\mathrm{mp}} / \mathrm{d} \phi$, is calculated from the slope of the function $R_{\mathrm{p}}=f(\phi)$ and is presented in Table 6. The microscopic polarisation parameters can be determined with Equations 21 and 29 if we assume that at very low volume fractions flocculation or chain formation is negligible and therefore Equation 29 holds.

Table 6. Polarisation parameters obtained from experimental data and compared with $\phi_{a}$ and $\phi_{c r}$

\begin{tabular}{|c|c|c|c|c|c|}
\hline Suspended material & $M K O H$ & $\phi_{c r}$ & $\phi_{a}$ & $\phi_{\max }$ & $\left(\frac{d R_{m p}}{d \phi}\right)$ \\
\hline $\mathrm{B}_{4} \mathrm{C}$ & $10^{-3}$ & 0.21 & 0.52 & - & 9.5 \\
\hline $\mathrm{NbB}_{2}$ & $10^{-3}$ & 0.17 & 0.17 & - & 11.5 \\
\hline $\mathrm{NbC}$ & $10^{-3}$ & 0.05 & - & - & 10.7 \\
\hline $\mathrm{NbN}$ & $10^{-3}$ & 0.17 & - & - & 16.7 \\
\hline $\mathrm{TaC}$ & $10^{-3}$ & 0.11 & - & - & 2.3 \\
\hline TiN & $10^{-3}$ & 0.04 & - & - & 1.7 \\
\hline $\mathrm{VC}$ & $10^{-3}$ & 0.27 & 56 & - & 4.0 \\
\hline $\mathrm{VC}$ & 2 & 0.40 & - & - & 32.8 \\
\hline VN & $10^{-2}$ & 0.22 & - & - & 22.1 \\
\hline VN & 2 & 0.18 & - & - & 4.0 \\
\hline $\mathrm{ZrC}$ & $10^{-3}$ & 0.28 & 0.59 & 0.38 & 4.7 \\
\hline Graphite (ks 5-10) & $10^{-3}$ & 0.01 & - & - & - \\
\hline Graphite (ks 5-10) & $10^{-2}$ & 0.09 & - & 0.018 & 39.0 \\
\hline Graphite (ks 25) & $10^{-2}$ & 0.09 & 0.19 & 0.026 & 31.8 \\
\hline Graphite (ks 44) & $10^{-2}$ & 0.11 & - & 0.036 & 22.3 \\
\hline Graphite (ks 10) & $10^{-2}$ & 0.002 & - & 0.021 & 40.8 \\
\hline Graphite (ks 75) & $10^{-2}$ & 0.17 & 0.33 & 0.066 & 17.8 \\
\hline Graphite (ks 5-75) & 2 & 0.04 & - & - & 11.0 \\
\hline Copper (M) & $10^{-3}$ & 0.11 & - & - & 18.2 \\
\hline Copper (M) & $10^{-2}$ & 0.14 & - & - & 22.7 \\
\hline Copper (RdH) & $10^{-3}$ & 0.08 & - & - & 33.3 \\
\hline Zinc & $10^{-3}$ & 0.003 & - & - & 11.1 \\
\hline Zinc $\left(1 \% \mathrm{~B}_{4} \mathrm{C}\right)$ & 2 & 0.33 & - & 0.22 & 14.2 \\
\hline Zinc $\left(1 \% \mathrm{~B}_{4} \mathrm{C}+\mathrm{S}.\right)$ & 2 & 0.44 & - & 0.24 & 6.5 \\
\hline Zinc $(1 \%$ At. $)$ & 2 & 0.07 & - & - & 5.2 \\
\hline Zinc ( $1 \%$ At.) & 12 & 0.18 & - & - & 5.0 \\
\hline $\operatorname{Zinc}(1 \%$ At. $+0.5 \mathrm{M} \mathrm{ZnO})$ & 12 & 0.013 & - & 0.06 & 14.2 \\
\hline
\end{tabular}




\section{Conclusions}

The impedance technique is very useful for determination of the conductivity of two-phase systems such as slurry and suspension electrodes as well as fluidizedbed electrodes. Results obtained for a number of suspensions with conducting particles show that the conductivity strongly depends on the frequency and it is argued that the low and high frequency limits of the conductivity are meaningful parameters of the twophase system. The suspension systems reveal a large difference between the high and low frequency conductance, which points to a considerable surface polarisation contribution. This implies that arbitrary chosen frquencies for these measurements as seen in the literature will include an unknown particle-surface polarisation contribution and are therefore less reliable conductivity data.

The aspects of agglomeration or chain formation for suspensions are related to the attraction of the suspended particles by the Van der Waals-London dispersive forces and to electrostatic repulsion. Different models for suspension systems are discussed.

Fits of the Bruggeman model for flocculated particles can give a good agreement with experimental data but the parameters found are not always physically meaningful. The symmetric Bruggeman theory, for the case of chain formation, gives no good agreement with the experiments. The GEM model gives generally a good fit for the experimental results and shows in general a lower variance with experimental data than other models.

In the case of a fit with the Bruggeman model, but also with the GEM model, the measured particle conductance is much lower than that predicted from particle-conductivity data. An extra resistance contribution can be found in the large contact resistance between the particles due to constriction and film resistances; also a poor wetting of the particles increases this resistance.

Microscope photographs indicate a higher percolation threshold for zinc and graphite than found with the GEM theory; however, a common trend of this threshold with the maximum of the polarisation resistivity is found. The measured decrease of the polarisation resistivity after the maximum reveals the occurrence of percolation, which may result in shortcircuiting of the microscopic polarisation resistances. These phenomena indicate chain formation of the particles. For graphite suspensions this effect shifts to higher volume fractions with increasing particle size.

With increase of ionic strength the conductance of the suspension decreases and the percolation threshold increases.

\section{Acknowledgements}

We gratefully thank Dr J. Lavèn and H. Zeilmaker for their valuable suggestions and critical reading of the manuscript.
References

[1] R. Landauer (edited by J. C. Garland and D. B. Tanner), 'Electric Transport and Optical Properties of Inhomogeneous Media', AIP Conference Proceedings, no. 40, American Institute of Physics, (New York, 1978).

[2] J. C. Maxwell, 'A Treatise on Electricity and Magnetism', 2nd ed. Vol. 1, Clarendon Press, Oxford (1881).

[3] R. E. De La Rue and C. W. Tobias, J. Electrochem. Soc. 106 (1959) 827.

[4] R. E. Meredith, in 'Advances in Electrochemistry and Electrochemical Engineering', Vol. 2 (edited by C. W. Tobias), Interscience Publishers, New York (1962) p. 15.

[5] D. A. G. Bruggeman, Ann. Phys. (Lpz) 24 (1935) 636.

[6] R. E. Meredith and C. W. Tobias, J. Electrochem. Soc. 108 (1961) 286.

[7] D. A. G. Bruggeman, Ann. Phys. (Lpz) 24 (1935) 665, 25 (1936) 645, 29 (1937) 160, Phys. Z. 37 (1936) 906, 92 (1934) 561.

[8] D. S. McLachlan, J. Phys. C, Solid State Phys. 18 (1985) 1891.

[9] Idem, ibid. 19 (1986) 1339.

[10] Idem, ibid. 20 (1987) 865.

[11] P. Daleshinamurthy, Ch. V. Ramachandramurthy, V. Subrahmanyam and K. S. Rajandam, J. Techn. (India) 21 (1981) 1479.

[12] H. Fricke, Phys. Rev. 24 (1903) 575.

[13] C. A. R. Pearce, Br. J. Appl. Phys. 6 (1955) 113.

[14] N. A. Seaton and E. D. Glandt, Physico Chemical Hydrodynam. 9 (1987) 369.

[15] S. Bhattacharya, J. P. Stokes, M. W. Kim and J. S. Huang, Phys. Rev. Lett. 55 (1985) 1884.

[16] B. Lagourette, J. Peyrelasse, C. Boned and M. Clausse, Nature 281 (1979) 60.

[17] J. Fang, R. L. Vanable, J. Colloid Interface Sci. 116 (1987) 269.

[18] J. C. R. Turner, AIChE Symp. Ser. 69 (1973) 115

[19] P. LeGoff, F. Vergnes, F. Coeuret and J. Bordet, Ind. Eng. Chem. 61 (1969) 8.

[20] J. N. Hiddleston and A. F. Douglas, Electrochim. Acta 15 (1970) 431.

[21] G. Kreysa, ibid. 25 (1980) 813.

[22] D. C. Eardley, D. Handley and S. P. S. Andrew, ibid. 18 (1973) 839.

[23] D. Handley and D. C. Eardley, Chem. Ind. 20 (1975) 330

[24] B. J. Sabacky and J. W. Evans, Metall. Trans. B 8(1977) 5.

[25] S. Abdallah, Ph. D Thesis, University of Paris 6 (1988).

[26] M. Fleischmann and J. W. Oldfield, J. Electroanal. Chem. 29 (1971) 231.

[27] M. Fleischmann, J. W. Oldfield and L. Tennakoon, J. Appl. Electrochem. 1 (1971) 103.

[28] W. P. M. van Swaay, A. A. C. M. Beenackers and A. Welmers, Procestechniek 31 (1976) 458.

[29] A. A. C. M. Beenackers, W. P. M. van Swaay and A. Welmers, Electrochim. Acta 22 (1977) 1277.

[30] P. J. Sonneveld, W. Visscher, E. Barendrecht, J. Appl. Electrochem. 20 (1990) 563.

[31] P. J. Sonneveld, Ph. D Thesis, Eindhoven University of Technology (1991).

[32] G. R. Ziegner and W. R. Schowalter, AIChE J. 23 (1977) 243.

[33] J. H. Schenkel and J. A. Kitchener, Trans. Faraday Soc. 56 (1960) 161.

[34] W. R. Schowalter, Ann. Rev. Fluid. Mech. 16 (1984) 245.

[35] 'Landolt-Börnstein Tabellen', II Bd., 7 Teil, SpringerVerlag, Berlin (1960).

[36] G. V. Samsonov and I. M. Vinitskii, 'Handbook of Refractory Compounds', IFI/Plenum, New York (1980); 'Handbook of Chemistry and Physics', 61st edn., CRC Press (1980-81).

[37] J. Theodoor and G. Overbeek, Adv. Colloid Interface Sci. 16 (1982) 17.

[38] R. I. Feigin and D. H. Napper, J. Colloid Interface Sci. 75 (1980) 525.

[39] T. F. Tadros, Adv. Colloid Interface Sci. 12 (1980) 141.

[40] Idem, Chem. Ind. (Lond.) 15 (1980) 211.

[41] R. Hogg and K. C. Yang, J. Colloid Interface Sci. 56 (1976) 573.

[42] H. B. Weiser and W. O. Milligan, J. Phys. Chem. 44 (1940) 1081. 
[43] D. Bedeaux, M. M. Wind and M. A. van Dijk, Z. Phys. B68 (1987) 343.

[44] L. Thomas and K. H. McCorke, J. Colloid Interface Sci. 36 (1971) 110.

[45] M. Sahimi, B. D. Hughes, L. E. Scriven, H. T. Davis, $J$. Phys. C., Solid State Phys. 16 (1983) 521.

[46] M. A. J. Michels, J. C. M. Brokken-Zijp, Ned. Tÿdschr. Natuurkd. A55(3) (1989), 93.

[47] M. A. J. Michels, J. C. M. Brokken-Zijp, W. M. Groen- ward and A. Knoester, Physica A157 (1989) 529.

[48] K. Ghowsi and R. J. Gale, J. Electrochem. Soc. 136 (1989) 2806.

[49] R. Holm, 'Electric Contacts: Theory and Applications', Springer, New York (1967).

[50] K. Kendall, Powder Technol. 62 (1990) 147.

[51] A. L. Horvath, 'Handbook of Aqueous Electrolyte Solutions', John Wiley \& Sons, New York (1985). 